\title{
Extracellular Vesicles in Tumors: A Potential Mediator of Bone Metastasis
}

\author{
Shenglong $\mathrm{Li}^{1,2 \star}$ and Wei Wang ${ }^{1 *}$ \\ ' Department of Bone and Soft Tissue Tumor Surgery, Cancer Hospital of China Medical University, Liaoning Cancer Hospital \\ and Institute, Shenyang, China, ${ }^{2}$ Department of Tissue Engineering, Center of 3D Printing \& Organ Manufacturing, School \\ of Fundamental Sciences, China Medical University, Shenyang, China
}

\section{OPEN ACCESS}

Edited by:

Roberta Tasso,

University of Genoa, Italy

Reviewed by:

Gemma Di Pompo,

Rizzoli Orthopedic Institute (IRCCS),

Stefano Fais,

Italy
Fais,

National Institute of Health (ISS), Italy

*Correspondence:

Shenglong $L$

lishenglong@cancerhosp-In-cmu.com

Wei Wang

wangwei801027@sina.cn

Specialty section:

This article was submitted to

Molecular and Cellular Oncology,

a section of the journal

Frontiers in Cell and Developmental

Biology

Received: 09 December 2020

Accepted: 11 March 2021

Published: 01 April 2021

Citation:

Li S and Wang W (2021)

Extracellular Vesicles in Tumors:

A Potential Mediator of Bone

Metastasis

Front. Cell Dev. Biol. 9:639514. doi: 10.3389/fcell.2021.639514
As one of the most common metastatic sites, bone has a unique microenvironment for the growth and prosperity of metastatic tumor cells. Bone metastasis is a common complication for tumor patients and accounts for $15-20 \%$ of systemic metastasis, which is only secondary to lung and liver metastasis. Cancers prone to bone metastasis include lung, breast, and prostate cancer. Extracellular vesicles (EVs) are lipid membrane vesicles released from different cell types. It is clear that EVs are associated with multiple biological phenomena and are crucial for intracellular communication by transporting intracellular substances. Recent studies have implicated EVs in the development of cancer. However, the potential roles of EVs in the pathological exchange of bone cells between tumors and the bone microenvironment remain an emerging area. This review is focused on the role of tumor-derived EVs in bone metastasis and possible regulatory mechanisms.

Keywords: extracellular vesicles, osteoblast, osteoclast, bone metastasis, tumor

\section{INTRODUCTION}

Malignant tumors are the second leading cause of death worldwide. Distant metastasis of tumor cells is the most common cause of cancer-related death (Krzeszinski and Wan, 2015; Hiraga, 2019; Karayazi Atici et al., 2020). Bone is a major target for cancer metastasis, only secondary to the lung and liver (Yin et al., 2005; Su et al., 2015). Bone has a unique anatomical and physiopathological state that enhances the metastasis of different cancer types, including prostate, breast, lung, and gastric cancer and melanoma (Liu et al., 2020; Ma et al., 2020; Wang et al., 2020). Tumor cells may migrate from their original location to distant skeletal tissues, where they may exhibit accelerated growth and infiltrate surrounding tissues to form distant metastasis, characteristics associated with the heterogeneity of tumors (Zhang et al., 2019; Scimeca et al., 2020). Various physiopathological processes will be induced by the occurrence of affected bones and metastatic tumor cells, such

Abbreviations: EV, extracellular vesicle; miRNAs, micro RNAs; circRNAs, circular RNAs; lncRNAs, long non-coding RNAs; FGFs, fibroblast growth factors; IGFs, insulin-like growth factors; PTH-rP, parathyroid hormone-related protein; RANKL, receptor activator for nuclear factor- $\mathrm{\kappa B}$ ligand; TGF- $\beta$, transforming growth factor- $\beta$; DTC, disseminated tumor cells; PCa, prostate cancer; $\mathrm{BCa}$, breast cancer; LCa, lung cancer; MM, multiple myeloma; AML, acute myelocytic leukemia; PLD2, phospholipase D2; VCAM1, vascular cell adhesion molecule 1; AREG, amphiregulin; cAMP, adenosine monophosphate; EGFR, epidermal growth factor receptor ligands; MVB, multivesicular body; TSG101, Wilms tumor type 101 protein; Alix, ALG-2 interacting protein X; TDEs, tumor-derived exosomes; TME, tumor microenvironment; mTOR, mammalian target of rapamycin. 
as the adhesion molecules secreted by tumor cells bound to trabecular bone and stromal cells. Additionally, tumor cells can induce angiogenesis and bone absorption factors (Zhang et al., 2019). Once patients develop bone metastasis, there are no effective therapeutic strategies, and the 5-year survival rate of these patients is significantly lower. Moreover, bone metastasis may be accompanied by many complications (e.g., serious bone pain, pathological fracture, hypercalcemia, and spinal cord compression) that affect a patient's life expectancy and quality of life (Krzeszinski and Wan, 2015; Vicent et al., 2015; Yao et al., 2020).

In recent years, the mechanisms underlying bone metastasis have been a hot research topic, and more and more data support the "seed and soil" theory, which says that tumor cells can only grow in a microenvironment suitable for their growth (Marazzi et al., 2020; Tamura et al., 2020; Yao et al., 2020). Thus, they form metastatic lesions in specific tissues and organs. Primary tumor cells proliferate, invade blood vessels, and form tumor blood vessels. Tumor cells reach each system in the body through the vasculature, proliferate in the microenvironment of specific organs and tissues suitable for their growth, destroy normal tissue structures, and form metastatic lesions. Bone metastasis involves two processes: (1) cancer cells reach bone by a certain pathway; (2) cancer cell survival and growth in the bone. Under normal conditions, the activities of osteoblasts and osteoclasts are balanced (Laranga et al., 2020; Wang et al., 2020). When bone metastasis occurs, this balance is disrupted, and the higher cell activity determines whether the bone metastasis is osteogenic or osteolytic. Osteogenic bone metastasis is the result of the activation of osteoblasts and the inhibition of osteoclasts. Conversely, osteolytic bone metastasis involves the activation of osteoclasts and the inhibition of osteoblasts (Wood and Brown, 2020).

Extracellular vesicles (EVs) are bi-layered membrane vesicles with a diameter of $30-100 \mathrm{~nm}$ secreted into the microenvironment via exocytosis by multiple cells. EVs are rich in many components, including cell-specific proteins, lipids, and RNA (i.e., mRNA, miRNA, and other non-coding RNA) (Dai et al., 2020; Yang E. et al., 2020). These vesicles are secreted by multiple cell types (e.g., tumor cells, macrophages, and fibroblasts) and are widely distributed in the blood, urine, ascites, synovial fluid, breast milk, and other body fluids. EVs carry and transmit important signaling molecules that affect the physiological and pathological state of their target cells (Cheng et al., 2020; LeBleu and Kalluri, 2020). Studies have shown that EVs participate in intercellular communication, immune responses, angiogenesis, and tumor cell growth (Yi et al., 2020). They have now been discovered in multiple cell types. Indeed, tumor cell-derived EVs have become a hot research area in the field of cancer (Tamura et al., 2020), and there have been many reports on EVs in cancer. For instance, EVs may release self-carrying cytokines to enhance the occurrence, development, proliferation, and migration of tumors and make tumors drug-resistant (Vasconcelos et al., 2019; Wortzel et al., 2019). In addition, the anticancer activity of miR-124 delivered by BM-MSC-associated EVs can act on the proliferation, epithelial-mesenchymal transition, and chemotherapy sensitivity of pancreatic cancer cells (Xu Y. et al., 2020). Endometrial cancer cells can promote M2-like macrophage polarization by delivering exosomal miRNA-21 under hypoxia conditions (Xiao et al., 2020). Furthermore, exosomal miR-92a-3p derived from highly metastatic cancer cells promotes the epithelial-mesenchymal transition and the metastasis of low-metastatic cancer cells by regulating the PTEN/Akt pathway in hepatocellular carcinoma (Yang B. et al., 2020). Moreover, neuroblastoma-secreted EVs carrying miR-375 promote osteogenic differentiation of bone marrow mesenchymal stromal cells (Colletti et al., 2020).

In recent years, many studies have demonstrated that tumor-derived EVs are an important component of the microenvironment of bone tumors. This article reviews the roles of tumor-derived EVs in bone metastasis and their potential molecular mechanisms and provides new insights for inhibiting bone metastasis.

\section{GENERATION, COMPOSITION, AND MAJOR BIOLOGICAL FUNCTIONS OF EXTRACELLULAR VESICLES}

The formation of EVs mainly involves four processes, including sprouting, invagination, multivesicular body formation, and secretion (Mathew et al., 2020; Zhang Y. et al., 2020). EVs are generated in endosomes. Invagination of the cell membrane results in the formation of early endosomes, and late endosomes sprout inward to form luminal vesicles that are transformed into multivesicular bodies (MVBs) with multiple small vesicles. After the MVBs fuse with the cell membrane, the inner vesicles sink again, and granular vesicles sprout and are released out of the cell as EVs (Li et al., 2020; Naseri et al., 2020). Upon reaching recipient cells, the EVs release their contents in specific cells through ligand binding, phagocytosis, and fusing with the cell membrane to change the physiological state and function of cells (Huyan et al., 2020).

Extracellular vesicles are mainly composed of proteins, nucleic acids, and lipids (Kalluri and LeBleu, 2020; Zhao X. et al., 2020). All EVs express membrane-bound proteins, such as tetraspanin (CD9, CD63, CD81, and CD82), which may be used as biomarkers and are associated with the biogenetic derivation of EVs (Mathieu et al., 2019; Pegtel and Gould, 2019). EVs derived from different cells express specific proteins, such as ALG-2 interacting protein X (ALix), Wilms tumor type 101 protein (TSG101), and heat shock protein HSP70, and are associated with specific cell functions. EVs also include nucleic acids, such as mRNA, miRNA, and lncRNA (Mathew et al., 2020; Zhang Y. et al., 2020). These nucleic acids fuse with target cells and regulate protein expression and signaling in recipient cells. The lipids in the EVs include cholesterol, diacylglycerol, and phospholipid (Mathew et al., 2020; Zhang Y. et al., 2020). The lipids not only participate in the formation and maintenance of EV morphology but also participate in intercellular communication as signal molecules. These contents are transported to target cells via body fluids and are implicated in angiopoiesis and the occurrence, development, and metastasis of tumors (Kalluri and LeBleu, 2020; Slomka et al., 2020; Zhao X. et al., 2020; Zhang Y. et al., 2020; 


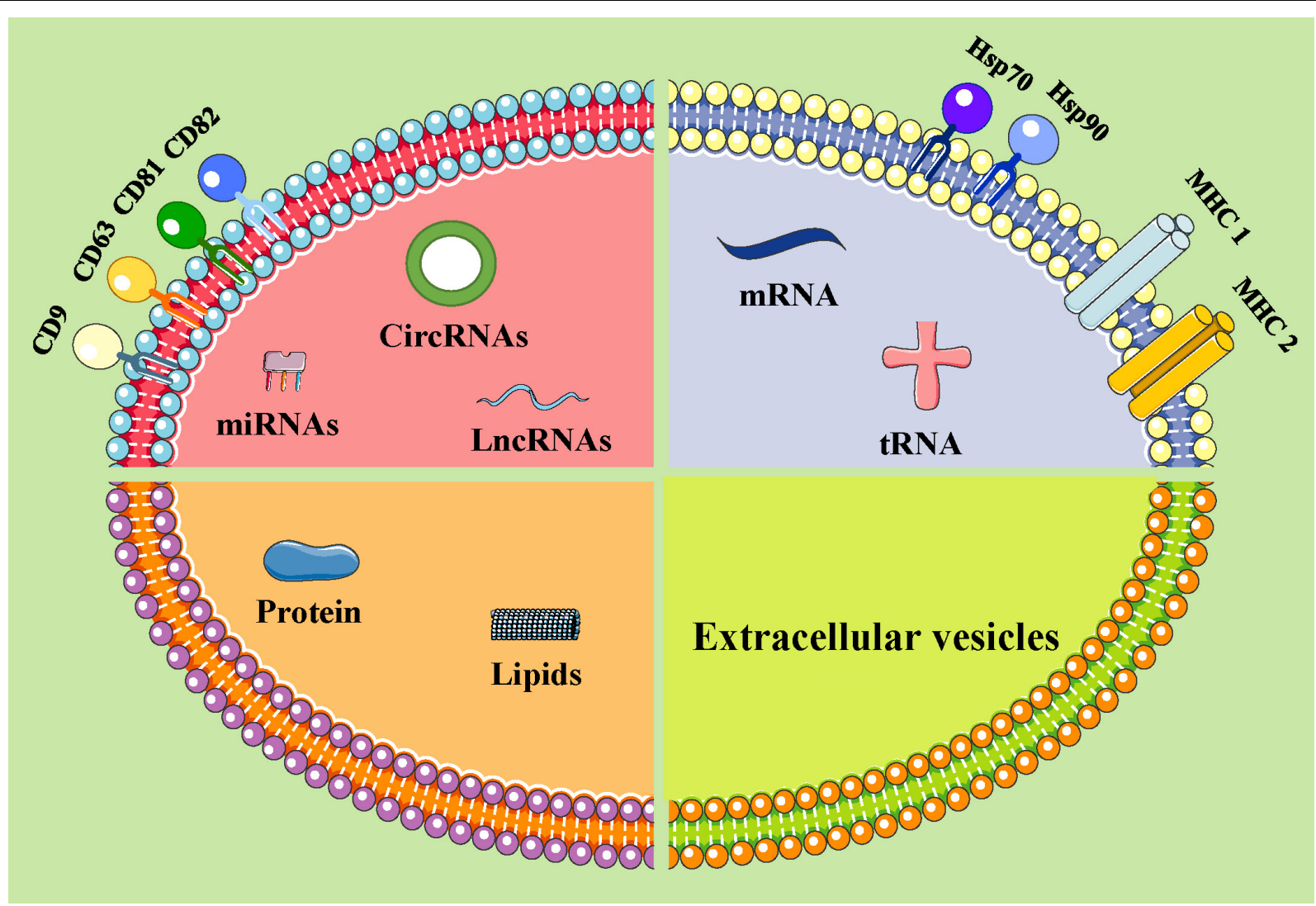

FIGURE 1 | The components of extracellular vesicles (ideograph). EVs can be secreted by various types of cells. EVs carry a variety of proteins, lipids, DNA, mRNA, and non-coding RNAs. Moreover, EV surface proteins contain the following substances: MHC class I/II molecules, heat shock proteins (HSP70, HSP90), and four transmembrane family proteins (CD63, CD9, CD81, and CD82, etc.). miRNAs, microRNAs; IncRNAs, long non-coding RNAs; circRNAs, circular RNAs; mRNAs, messenger RNA; tRNA, transfer RNA.

Figure 1). Potential exosomal biomarkers and clinical targets are displayed in Table 1.

Extracellular vesicles are important carriers for intercellular communication, immunoregulation, and disease diagnosis and prognostic markers (Melo et al., 2015; Tang et al., 2018). Circulating EVs can be used as non-invasive biomarkers and liquid biopsies for early detection, diagnosis, and treatment of cancer (Kalluri, 2016; Hsu et al., 2017; Pan et al., 2017; Fu et al., 2018; Goto et al., 2018). For example, EVs derived from chronic myelogenous leukemia cells contain the cytokine TGF $\beta 1$, which binds to the TGF $\beta 1$ receptor on leukemia cells, thereby promoting tumor growth by activating ERK, Akt, and anti-apoptotic pathways (Raimondo et al., 2015). Many tumor types are dependent on mitochondrial metabolism by triggering adaptive mechanisms to optimize their oxidative phosphorylation with respect to substrate supply and energy demands. Exogenous EVs may induce metabolic reprogramming through the recovery of cancer cell respiration and the suppression of tumor growth (Tomasetti et al., 2017). Lugini et al. (2016) found that EVs from human colorectal cancer induce a tumor-like behavior in colonic mesenchymal stromal cells, which may be involved in cancer progression or interfere with cancer. Cossetti et al. (2014) discovered that somatic RNA is transferred to sperm cells, which can therefore act as the final recipients of somatic cell-derived information.

Exosomal miRs involved in the modulation of cancer metabolism may potentially optimize diagnosis and therapy (Le et al., 2014; Zhou et al., 2014; Tominaga et al., 2015; Baroni et al., 2016; Zheng et al., 2017). Moreover, tumor-derived exosomes (TDEs) are implicated in the formation and progression of different cancer processes, including tumor microenvironment (TME) remodeling, angiogenesis, metastasis, invasion, and drug resistance (Mashouri et al., 2019). In recent years, the study of EVs has become a new direction for further applied research. For glioblastoma patients, an invasive blood sample is used to diagnose and follow the response to therapy. The protein cargo of plasma GBM EVs can be used to detect a tumor, characterize its molecular profile, and tailor treatment (Osti et al., 2018). In addition, high levels of EVs in the plasma of melanoma patients represent a method for clinical management through the expression of CD63 and caveolin-1 (Logozzi et al., 2009). Rodríguez Zorrilla et al. (2019) also found CD63 expression induced by a dramatic reduction in plasmatic EV after surgical treatment in oral squamous cell carcinoma (OSCC) patients. Lower plasma EV levels correlated with a better life expectancy in OSCC patients (Rodríguez Zorrilla et al., 2019). Expression of 
TABLE 1 | Potential exosomal biomarker and targets in a clinical setting.

\begin{tabular}{|c|c|c|c|c|}
\hline Cargo & Type & Signaling pathway & EVs function & References \\
\hline TGF $\beta 1$ & Protein & $\begin{array}{c}\text { Activating ERK, Akt, and anti-apoptotic } \\
\text { pathway }\end{array}$ & Promotes tumor growth & $\begin{array}{l}\text { Raimondo et al., } \\
2015\end{array}$ \\
\hline E-cadherin & Protein & $\begin{array}{l}\text { Activating } \beta \text {-catenin and NF-kB } \\
\text { signaling pathway }\end{array}$ & Angiogenesis & Tang et al., 2018 \\
\hline $\operatorname{miR}-23 a$ & miRNA & Targeted to ZO1 & $\begin{array}{l}\text { Increases vascular } \\
\text { permeability and } \\
\text { cancer migration }\end{array}$ & Hsu et al., 2017 \\
\hline $\begin{array}{l}\text { miRNA-191, miR-21, } \\
\text { miR-451a }\end{array}$ & miRNAs & / & $\begin{array}{c}\text { Biomarkers for } \\
\text { pancreatic cancer }\end{array}$ & Goto et al., 2018 \\
\hline $\begin{array}{l}\text { miR-17-5p } \\
\text { miR-92a-3p }\end{array}$ & miRNAs & / & $\begin{array}{l}\text { Biomarkers for colon } \\
\text { cancer }\end{array}$ & Fu et al., 2018 \\
\hline Glypican-1 & Protein & / & $\begin{array}{l}\text { Biomarkers for } \\
\text { pancreatic cancer }\end{array}$ & Melo et al., 2015 \\
\hline MET & Protein & Activating MET signaling & $\begin{array}{l}\text { Priming premetastatic } \\
\text { niches }\end{array}$ & $\begin{array}{l}\text { Peinado et al., } \\
2012\end{array}$ \\
\hline miR-9 & miRNA & / & $\begin{array}{l}\text { Increasing cancer } \\
\text { growth }\end{array}$ & $\begin{array}{l}\text { Baroni et al., } \\
2016\end{array}$ \\
\hline $\mathrm{miR}-21$ & miRNA & Regulating PTEN/PI3K/AKT pathway & $\begin{array}{l}\text { Inhibits apoptosis and } \\
\text { increase drug } \\
\text { resistance }\end{array}$ & $\begin{array}{l}\text { Zheng et al., } \\
\qquad 2017\end{array}$ \\
\hline $\begin{array}{l}\text { miR-105, miR-181c, } \\
\text { miR-200 }\end{array}$ & miRNAs & / & Increases metastasis & $\begin{array}{l}\text { Le et al., 2014; } \\
\text { Zhou et al., 2014; } \\
\text { Tominaga et al., } \\
2015\end{array}$ \\
\hline ZFAS1 & IncRNA & Regulating MAPK signal and EMT & $\begin{array}{l}\text { Increases cancer } \\
\text { growth and metastasis }\end{array}$ & Pan et al., 2017 \\
\hline
\end{tabular}

both CD81 and PSA are high only in prostate cancer patients, and the levels of tumor biomarkers (e.g., PSA-EVs) may represent a prostate cancer diagnosis (Logozzi et al., 2017). Logozzi et al. (2019a) found that plasma EVs expressing PSA (Exo-PSA) could distinguish prostate cancer patients from healthy individuals both in specificity and sensitivity (Logozzi et al., 2019a).

\section{ROLES AND MECHANISMS OF THE BONE MICROENVIRONMENT IN BONE METASTASIS}

The tumor microenvironment plays an important role in tumor development by establishing interactions between host components and the tumor cells. Factors produced by tumor cells can alter the microenvironment at distant organs, generating pre-metastatic niches for subsequent metastasis. Pre-metastatic niche formation occurs as a sequence of events generated by the tumor cells that effectually prime the target site of disease for arrival, metastasis, and survival. Importantly, the existence of a pre-metastatic niche implies that metastasis to a particular organ is a predetermined event. Endothelial growth factor plays a critical role in the formation of the pre-metastatic niche. The bone microenvironment is rich with different cell types, including osteoblasts, osteoclasts, bone marrow stromal cells, immune cells, and vascular endothelial cells (Browne et al., 2014; Waning and Guise, 2014; Coleman et al., 2020). Osteoblasts and osteoclasts are key cell players in this microenvironment that induce osteolytic, osteogenic, or mixed bone metastasis
(Esposito and Kang, 2014; Croucher et al., 2016; Coleman et al., 2020). However, bone marrow stromal cells exert inhibitory effects on bone metastasis through the integrins $(\alpha \mathrm{v} \beta 3, \alpha 2 \beta 1$, $\alpha 4 \beta 1$ ), TGF $\beta$ family members, bone resident proteins (BSP, OPG, SPARC, OPN), RANKL, and PTHrP (Lipton, 2006; Esposito and Kang, 2014). Moreover, immune surveillance, immune killing, the formation of pre-metastatic lesions, the cooperation of osteoclasts and immune cells, and the bone nutrient supply of vascular endothelial cells are important during bone metastasis (Guise et al., 2006; Quayle et al., 2015; Yao et al., 2020). During this metastatic process, tumor cells interact with cells in the bone microenvironment (Coleman et al., 2020; Mukaida et al., 2020; Figure 2).

Cancer acidity has a major role in inducing increased EV release by human cancer cells. Previous studies demonstrated that low $\mathrm{pH}$ was a sign of tumor malignancy that could influence EV release and uptake by human cancer cell lines of different histotypes, particularly prostate cancer (Parolini et al., 2009; Logozzi et al., 2018). Besides, the acquisition of a osteoblastic/osteolytic phenotype, such as CAIX, has been detected both in vitro, increased by the low $\mathrm{pH}$ condition, and in the plasma of patients, where a clear enzymatic activity, together with a reduced intraluminal $\mathrm{pH}$ of EVs was seen (Logozzi et al., 2019b). Tumor acidity and EV levels are strongly related and contribute to the malignant tumor. Buffering, alkalinization, or anti-acidic treatment reduces EV levels in cancer cells. Furthermore, plasma EV levels allow for an early diagnosis of the disease. Therapeutic strategies are being actively pursued to counteract the 


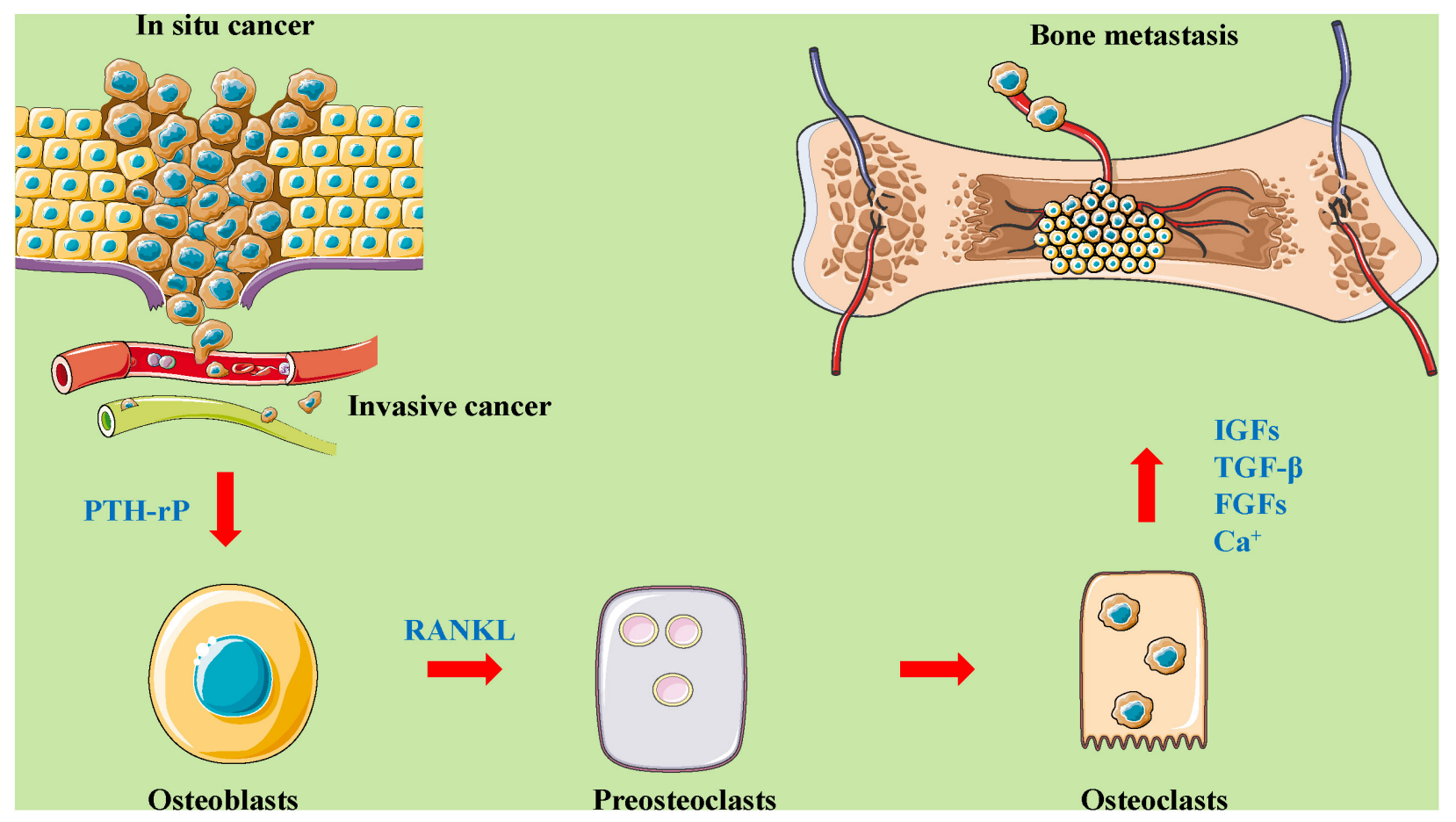

FIGURE 2 | The roles and mechanisms of the bone microenvironment in tumor metastasis to bone. A complex and abnormal cycle of bone metastasis involving mutual interactions between tumor cells, bone cells (osteoclasts and osteoblasts), and the bone matrix. As shown in this figure, in situ cancer cells enter the blood vessels, causing proliferation, migration, and invasion. Then, these cells act on osteoblasts by regulating PTH-rP, which affects preosteoclasts and osteoclasts through the mediation of a related protein (such as RANKL). Osteoblasts and osteoclasts affect bone metastases by mediating the expression and secretion of factors (for example, IGFs, TGF- $\beta$, FGFs, $\mathrm{CA}^{2+}$ ). FGFs, fibroblast growth factors; IGFs, insulin-like growth factors; PTH-rP, parathyroid hormone-related protein; RANKL, receptor activator for nuclear factor-кB ligand; TGF- $\beta$, transforming growth factor- $\beta$.

immunosuppressive and tumor-promoting activities of EVs (Logozzi et al., 2019c).

\section{Autoregulation of Tumor Cells}

The autoregulation of tumor cells is important for determining whether they maintain a latent, dormant state within the bone microenvironment long-term and is a key mechanism against autoimmunity and chemical drugs (Aguirre Ghiso, 2002; Sosa et al., 2014). When tumor cells encounter severe conditions (e.g., hypoxia, hypoglycemia, high acid environment), they may change the modification of proteins in the endoplasmic reticulum. In addition to inhibiting self-proliferation, tumor cells also control their quantity via autophagy (Aguirre Ghiso et al., 1999; Liu et al., 2002). The autophagy of tumor cells is mainly associated with the mammalian target of rapamycin (mTOR) (Malladi et al., 2016). In the case of cellular deficiency, mTORC1 kinase activity is reduced, which induces the autophagy of tumor cells, and they enter into a quiescent period. Tumor cells can also enter a Sox-dependent stem-like state and silence the Wnt signaling pathway, which are important for bone metastasis (Malladi et al., 2016). The autoregulation of tumor cells is a major mode of tumor cell cycle quiescence. When studying the influence of the bone microenvironment on metastatic factors, attention should be paid to the relationship between the bone microenvironment and the intrinsic factors of tumor cells.

\section{Osteoblasts and Tumor Cells}

The interaction between tumor cells and osteoblasts is mainly reflected in the promotion of tumor cell adhesion and colonization by osteoblasts. With continuous research on bone metastasis, more and more experiments have put forth the concept of "pre-metastatic lesions;" that is, after tumor cells reach the target organ, they become infiltrating tumor cells and enter a dormant period (i.e., no proliferation or activation in the short term, Ki67-negative) (Ren et al., 2015; Wang et al., 2018). However, in bone metastasis, the colonization of disseminated tumor cells (DTC) is closely associated with osteoblasts (Grudowska et al., 2017). In addition, Wang et al. (2015) showed that cell activation in early bone metastasis is associated with $\mathrm{N}-\mathrm{E}$ cadherin and $\mathrm{E}-\mathrm{E}$ cadherin on the cell membranes of osteoblasts. The binding of osteoblastic $N$-cadherin to $N$-cadherin on tumor cells activates the mTOR signaling pathway to enhance the activation and proliferation of dormant tumor cells. Moreover, osteoblasts are involved in the proliferation process following the activation of the quiescent tumor cells. Thus, osteoblasts participate in a "vicious cycle" between tumor cells and the bone microenvironment, whereby the destruction of the bone microenvironment and tumor cell proliferation promote each other by releasing vascular endothelial growth factor-(VEGF), matrix metalloproteinases (MMPs), thrombospondin, and inflammatory and coagulation 
factors (Hirshberg et al., 2014; Wang et al., 2015). Recent studies have shown that osteoblasts assist tumor cell colonization through receptors in the early stage of bone metastasis and mainly participate in the "vicious cycle" to promote tumor proliferation in the late stage of bone metastasis (Weilbaecher et al., 2011; Hirshberg et al., 2014).

\section{Osteoclasts and Tumor Cells}

Osteoclasts are an important promoting factor during bone metastasis. At the early stage of bone metastasis, vascular cell adhesion molecule-1 (VCAM1) and the integrin family are important molecules mediating the relationship between tumor cells and osteoclasts (Lu et al., 2011). High VCAM1 levels in tumor cells interact with osteoclast-expressed $\alpha 4 \beta 1$ integrin, which may recruit osteoclast precursor cells, initiate the osteoclast process, and ultimately induce the osteolytic clinical manifestations of bone metastasis (Lu et al., 2011). The "vicious cycle" in the bone microenvironment starts with the beginning of the osteoclast process. Current research has demonstrated that osteoclasts are important in bone metastasis and remodeling. As important effector cells, specific inhibition of the tumor-osteoclast process greatly improves the quality of life of patients with bone metastasis (Kelly et al., 2005). The biomarker PTHrP(12-48) can stimulate the expression of cleaved caspase 3 in OCLs and their precursors, causing apoptosis (Kamalakar et al., 2017). PCAT7 is a potential therapeutic target against bone metastasis of PCa via the TGF- $\beta$ signaling pathway (Lang et al., 2020). Zoledronate enhances osteoclast differentiation through the IL-6/RANKL signal pathway in osteocyte-like MLO-Y4 cells (Kim et al., 2019).

\section{Bone Marrow Stromal Cells and Tumor Cells}

After tumor cells infiltrate the bone marrow, bone marrow stromal cells are important for tumor cell dormancy (Dormady et al., 2000). A recent study indicated that bone marrow stromal cells have an inhibitory effect on tumor cells. It is often necessary to overcome these inhibitory processes to activate dormant tumor cells (Kobayashi et al., 2011). This is also a key target for researchers to design anti-tumor cell drugs to inhibit tumor metastasis and growth.

\section{Immune Cells and Tumor Cells}

An important relationship has been observed between tumor cells as special antigens in vivo and autoimmune cells. After tumor cells reach the bone microenvironment, they promote the growth of $\mathrm{CD} 6^{+} \mathrm{CD}^{+} \mathrm{T}$ cells and memory $\mathrm{CD} 4^{+} \mathrm{T}$ cells in the bone microenvironment (Feuerer et al., 2001). There is a significant association between $\mathrm{CD}^{+} \mathrm{T}$ cells and the incubation period of tumor metastasis as $\mathrm{CD} 8^{+} \mathrm{T}$ cells, as important cells for adaptive immunity, directly kill tumor cells. However, studies have shown that infiltrating dendritic plasma cells continuously release Th2 signals, inhibit $\mathrm{CD}^{+} \mathrm{T}$ cells, and promote the maturation of regulatory $\mathrm{T}$ cells and dormant tumor growth (Feuerer et al., 2001). A reduction in PDC slows down the activation process for bone metastasis. Depletion of $\mathrm{CD}^{+}$and $\mathrm{CD}^{+}{ }^{+} \mathrm{T}$ cells induces tumors to come out of dormancy and apoptosis and induces an increase in tumor cell Ki67, which increases their proliferation and activation (Sawant et al., 2012). Immune cells also participate in the activation of tumor cell dormancy by changing the process of bone remodeling (Sawant et al., 2012). With the rise of tumor immunotherapy, more attention is being paid to bone metastasis and immune cells. However, most of the current bone metastasis animal models are immunodeficient. Researchers should pay attention to the relationship between immune cells and bone metastasis (Kianercy and Pienta, 2016; Wu et al., 2016).

\section{Vascular Endothelial Cells and Tumor Cells}

After tumor cells reach the bone microenvironment, neovascularization becomes an important source of the nutrient supply. Endothelial cells surrounding the neovascularization secrete TGF- $\beta 1$ and periostin to induce the further proliferation of tumors (Mulcrone et al., 2017). VEGF- $\alpha$ is an important angiogenesis factor that plays an essential role in promoting the activation of tumor cell dormancy (Mulcrone et al., 2017). Nutrient supply is an important resource for cell growth. The study of nutrient supply channels is of great significance for not only bone metastasis but also for tumor metastasis in general and tumor growth in situ. In addition, it is essential to study vascular endothelial cells during bone metastasis.

\section{EXTRACELLULAR VESICLES AND BONE METASTASIS}

Recent studies have indicated that tumor-derived EVs play important roles in the microenvironment of bone tumors (Table 2 and Figure 3).

\section{Extracellular Vesicles and Prostatic Cancer Metastasis to Bone}

Prostatic cancer is the most common malignant tumor and an important cause of death, with gradually higher incidences and poor efficacies (Archer et al., 2020). Current therapies for prostatic cancer bone metastases continue to focus on reducing symptoms and improving quality of life in these patients. Bone metastases can result in many complications, such as refractory bone pain, hypercalcemia, pathologic fractures, and spinal cord compression, and can even cause more serious complications, such as permanent paralysis (Boucher et al., 2020; Xue et al., 2020). Therefore, an effective treatment strategy to reduce the rate of bone metastases and the associated complications is urgently needed in clinical practice to improve patient survival rates and quality of life.

In recent years, EVs have been reported to be essential for the metastasis of prostatic cancer to bones. Inder et al. (2014) showed that PC3-EVs could induce osteoblast proliferation and osteoclast differentiation. These effects have been shown to be reduced by cavin-1 expression in PC3 cells, which is an important discovery since cavin-1 has also been demonstrated to be a tumor suppressor in caveolin-1-positive prostate cancer. However, a 
TABLE 2 | Studies reporting the roles of tumor-derived extracellular vesicles in the development and progression of bone metastases.

\begin{tabular}{|c|c|c|c|c|c|c|c|c|c|}
\hline Tumor type & References & Origin of Evs & Isolation of Evs & $\begin{array}{c}\text { Characterization of } \\
\text { Evs }\end{array}$ & Exosomal RNAs & How to find & Validation of RNAs & Target cells & Underlying functions \\
\hline \multirow[t]{4}{*}{ Prostate cancer } & Inder et al., 2014 & $\begin{array}{l}\text { Prostate cancer } \\
\text { PC3 cells }\end{array}$ & Ultracentrifugation & / & Cavin-1/PTRF & / & Western blot & $\begin{array}{l}\text { Osteoblast and } \\
\text { osteoclast }\end{array}$ & $\begin{array}{l}\text { Induce osteoblast } \\
\text { proliferation, and } \\
\text { osteoclast } \\
\text { differentiation }\end{array}$ \\
\hline & Ye et al., 2017 & $\begin{array}{l}\text { MDA PCa 2b } \\
\text { cells }\end{array}$ & Ultracentrifugation & $\begin{array}{l}\text { TEM, NAT, western } \\
\text { blot (CD63, GM130) }\end{array}$ & miR-141-3p & / & RT-qPCR & Osteoblasts & $\begin{array}{c}\text { Promote osteoblastic } \\
\text { metastasis }\end{array}$ \\
\hline & Li et al., 2019 & LNCap cells & Ultracentrifugation & $\begin{array}{l}\text { TEM, NTA, western } \\
\text { blot (CD9, HSP70, } \\
\text { Alix) }\end{array}$ & miR-375 & $\begin{array}{l}\text { Small RNA } \\
\text { sequencing }\end{array}$ & RT-qPCR & $\begin{array}{l}\text { Osteoblasts } \\
\text { (hFOB1.19) }\end{array}$ & $\begin{array}{l}\text { Promote osteoblasts } \\
\text { differentiation }\end{array}$ \\
\hline & Borel et al., 2020 & C4-2B cells & Ultracentrifugation & $\begin{array}{l}\text { NTA, TEM, western } \\
\text { blot (Alix, CD9, } \\
\text { CLN3) }\end{array}$ & PLD2 & / & / & Osteoblasts & $\begin{array}{l}\text { Enhance osteoblast } \\
\text { activity }\end{array}$ \\
\hline \multirow[t]{3}{*}{ Breast cancer } & Kang, 2016 & $\begin{array}{l}\text { Breast cancer } \\
\text { cells }\end{array}$ & / & / & VCAM1 & $\begin{array}{l}\text { Gene expression } \\
\text { profiling }\end{array}$ & / & Osteoclasts & $\begin{array}{l}\text { Mediate the } \\
\text { recruitment of } \\
\text { pre-osteoclasts and } \\
\text { promote their } \\
\text { differentiation to mature } \\
\text { osteoclasts }\end{array}$ \\
\hline & Hashimoto et al., 2018 & $\begin{array}{l}\text { MDA-MB-231 } \\
\text { cell }\end{array}$ & Ultracentrifugation & $\begin{array}{l}\text { NTA, TEM, western } \\
\text { blot (CD9, TSG101) }\end{array}$ & miR-940 & $\begin{array}{l}\text { Microarray } \\
\text { analysis }\end{array}$ & RT-qPCR & / & $\begin{array}{l}\text { Induces extensive } \\
\text { osteoblastic lesions }\end{array}$ \\
\hline & Guo et al., 2019 & $\begin{array}{l}\text { MDA-MB-231 } \\
\text { cell }\end{array}$ & Ultracentrifugation & $\begin{array}{l}\text { TEM, western blot } \\
\text { (CD63, TSG101) }\end{array}$ & miR-20a-5p/SRCIN1 & / & RT-qPCR & Osteoclasts & $\begin{array}{l}\text { Enhances the } \\
\text { proliferation and } \\
\text { differentiation of } \\
\text { osteoclasts }\end{array}$ \\
\hline \multirow[t]{2}{*}{ Lung cancer } & Taverna et al., 2017 & CRL-2868 cells & Ultracentrifugation & $\begin{array}{c}\text { TEM, western blot } \\
\text { (Alix, TSG101, CD63) }\end{array}$ & AREG & 1 & 1 & Osteoclasts & $\begin{array}{l}\text { Enhance the } \\
\text { proliferation and } \\
\text { differentiation of } \\
\text { osteoclasts }\end{array}$ \\
\hline & Xu et al., 2018 & A549 cells & Exosomes isolation kit & $\begin{array}{l}\text { TEM, western blot } \\
\text { (CD63, TSG101) }\end{array}$ & miR-21/PDCD4 & / & RT-qPCR & Preosteoclasts & $\begin{array}{c}\text { Facilitate } \\
\text { osteoclastogenesis }\end{array}$ \\
\hline \multirow[t]{2}{*}{ Multiple myeloma } & Raimondi et al., 2015 & $\begin{array}{l}\text { Multiple } \\
\text { myeloma cells }\end{array}$ & $\begin{array}{l}\text { Ultracentrifugation, } \\
\text { sucrose purification }\end{array}$ & $\begin{array}{l}\text { DLS, western blot } \\
\text { (Alix, CD63) }\end{array}$ & 1 & / & / & Preosteoclast & $\begin{array}{c}\text { Modulate } \\
\text { pre-osteoclast } \\
\text { migration and } \\
\text { pro-differentiative role }\end{array}$ \\
\hline & Garimella et al., 2014 & 143B cells & $\begin{array}{c}\text { Differential } \\
\text { ultracentrifugation }\end{array}$ & NTA, TEM & CAMP & / & / & Osteoclasts & $\begin{array}{c}\text { Contain } \\
\text { pro-osteoclastic cargo }\end{array}$ \\
\hline $\begin{array}{l}\text { Acute myelocytic } \\
\text { leukemia }\end{array}$ & Kumar et al., 2018 & AML cells & Ultracentrifugation & $\begin{array}{l}\text { NTA, western blot } \\
\text { (TSG101, CD63) }\end{array}$ & Rab27a & / & / & Mesenchymal & $\begin{array}{l}\text { Block osteogenesis } \\
\text { and bone formation }\end{array}$ \\
\hline \multirow[t]{2}{*}{ Melanoma } & Mannavola et al., 2019 & Melanoma cells & Ultracentrifugation & $\begin{array}{c}\text { NTA, TEM, western } \\
\text { blot (CD81, TSG101, } \\
\text { CANX), flow } \\
\text { cytometry }\end{array}$ & CXCR4/CXCR7 & I & RT-qPCR & I & $\begin{array}{l}\text { Reprogram the innate } \\
\text { osteotropism of } \\
\text { melanoma }\end{array}$ \\
\hline & Peinado et al., 2012 & $\begin{array}{l}\text { Peripheral blood } \\
\text { of melanoma } \\
\text { subjects }\end{array}$ & $\begin{array}{l}\text { Ultracentrifugation, } \\
\text { sucrose purification }\end{array}$ & $\begin{array}{l}\text { TEM, western blot } \\
\text { (TYRP2, VLA-4, } \\
\text { HSP70, HSP90 } \\
\text { HSC70) }\end{array}$ & MET receptor & / & / & 1 & $\begin{array}{l}\text { Induce vascular } \\
\text { leakage at } \\
\text { pre-metastatic lesions }\end{array}$ \\
\hline
\end{tabular}

CAF, cancer-associated fibroblast; PAF, paracancer-associated fibroblast; AML, acute myeloid leukemia; TEM, transmission electron microscope; NTA, NanoSight NS300 particle size analyzer; DLS, dynamic light scattering. 


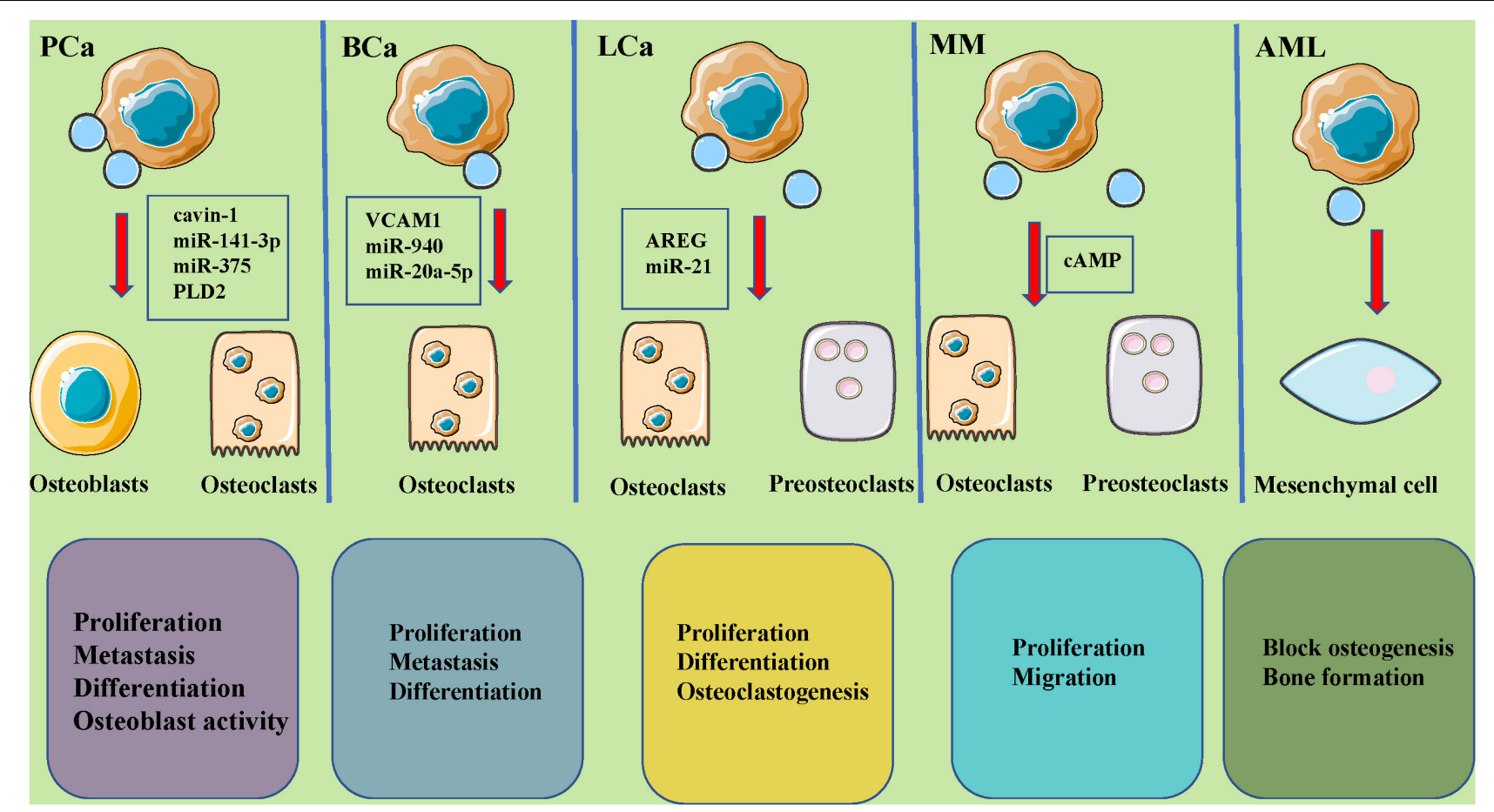

FIGURE 3 | The roles of tumor-derived extracellular vesicles in bone metastases and potential molecular mechanisms. EVs, secreted by PCa (cavin-1, miR-142-3p, miR-375, PLD2), BCa (VCAM1, miR-940, miR-20a-5p), LCa (AREG, miR-21), MM (cAMP), and AML tumors could carry different and abundant content and play a key role in osteoclastic and osteoblastic cycling, leading to various metastatic lesions. PCa, prostate cancer; BCa, breast cancer; LCa, lung cancer; MM, multiple myeloma; AML, acute myelocytic leukemia; TGFB2, transforming growth factor beta 2; AXL, AXL receptor tyrosine kinase; PLD2, phospholipase D2; VCAM1, vascular cell adhesion molecule 1; AREG, amphiregulin.

critical question remains, which concerns how cavin-1 expression selectively reduces EV levels in some molecules, including cargo, structural, and functional proteins, and miRNAs. Moreover, Ye et al. (2017) conducted a series of in vivo and in vitro studies and found that the MDA prostatic carcinoma (PCa) $2 \mathrm{~b}$ cell-derived exosomal miR-141-3p could transfer from EVs to osteoblasts and promote osteoblastic metastasis by regulating exosomal miR-141$3 p$ levels. These studies indicated that miRNAs could mediate cancer cell-to-osteoblast communication, which is important for the formation of bone metastases and osteogenic damage in PCa. Li et al. (2019) confirmed that high miR-375 expression was observed in LNCap-derived EVs that could preferentially reach osteoblasts and enhance osteoblast miR-375 levels. In addition, exosomal miR-375 might be associated with significantly higher osteoblast activity. Further investigations should be performed concerning the mechanisms underlying bone metastasis in PCa patients, and the molecular mechanisms underlying exosomal miR-375 involvement in the activation and differentiation of osteoblasts. Dai et al. (2019) confirmed that primary PCa cells could educate bone marrow to create a pre-metastatic niche via primary PCa EV-mediated transfer of PKM2 into bone marrow stem cells (BMSCs) with the subsequent upregulation of CXCL12. Furthermore, Borel et al. (2020) showed that phospholipase D2 (PLD2) stimulated EV secretion and enhanced osteoblast activity in PCa cell models. Therefore, PLD2 could be considered a potential player in establishing PCa bone metastases by acting through tumor cell-derived-EVs. EVs, released from prostate tumor cells, decreased DC-STAMP, TRAP, cathepsin K, and MMP-9 expression and thus decreased established markers for osteoclast fusion and differentiation. These findings suggest that tumor cell-derived microvesicles play an important role in cancer progression and disease aggressiveness (Terese et al., 2016).

\section{Extracellular Vesicles and Breast Cancer Metastasis to Bone}

Breast cancer is currently one of the most common malignant tumors in women worldwide, and the incidence of this disease has been rising in recent years. Breast cancer patients develop tumor metastasis during the advanced stages of disease. Bone tissue is one of the most common sites for metastases in patients with advanced breast cancer, and the metastatic ratio is much higher than that of the liver, lung, and kidney (Park et al., 2020; Zhang D. et al., 2020). Breast cancer metastasis to bones not only affects patient quality of life but also results in anemia, fractures, paraplegia, hypercalcemia, pain, cachexia, and increased mortality (Fico and Santamaria-Martinez, 2020). When breast tumors metastasize to bone, the balance between osteoblasts and osteoclasts is damaged. Osteoclasts are continuously activated, as manifested by higher osteoclast activity, resulting in osteolytic diseases with osteolysis and structural bone damage (Zhao Z. et al., 2020). Multiple bone growth factors are activated and released 
during bone resorption and remodeling, which provide an appropriate microenvironment for tumor cell growth, invasion, and metastasis (Zhao Z. et al., 2020). Once breast cancer cells have migrated to bone, the unique bone microenvironment could help to exchange biological information from the tumor cells to osteoblasts and osteoclasts, breaking the balance between osteolysis or osteogenesis during bone remodeling, which further results in fractures and pain and finally leads to death (Zhang D. et al., 2020; Pang et al., 2021). Although the tumors can be excised in clinical settings, tumor cells have often already spread and metastasized to bone, resulting in osteolytic lesions.

Previous studies have shown that EVs play key roles in breast cancer metastasis to bone. Lim et al. (2011) showed that the transfer of miRNAs from bone marrow stroma to breast cancer cells could involve the dormancy of bone marrow metastases. The results indicated that MDA-MB-231 and T47D breast cancer cells were arrested in the G0 phase of the cell cycle during co-culture with bone marrow stromal cells, and several miRNAs involved in cell proliferation were identified by analyzing miRNA expression profiles. These miRNAs included miR-127, miR-197, miR-222, and miR-223, that target CXCL12. Meanwhile, CXCL12-specific miRNAs were transported from bone marrow stroma to breast cancer cells via gap junctions, resulting in lower CXCL12 levels and reduced cell proliferation. Stroma-derived EVs containing miRNAs also contributed to breast cancer cell quiescence to a lesser degree than miRNAs transmitted via gap junctions. Kang (2016) showed that higher vascular cell adhesion molecule 1 (VCAM1) expression in disseminated breast tumor cells mediated the recruitment of preosteoclasts and promoted the differentiation of these cells to mature osteoclasts during bone metastasis formation. Bendinelli et al. (2017) clarified the control of the hepatocyte growth factor/mesenchymal-epithelial transition factor gene (HGF/Met) axis using DNA methylation and found that this axis was significantly involved in the supportive cell-metastatic cell nexus and metastatic outgrowths. This translational research focused on the effects of the microenvironment on breast cancer cell phenotypes and the formation of a pre-metastatic niche, and the colonization of these cells in bone. The results suggested the importance of targeting tumor microenvironments by blocking epigenetic mechanisms that control critical colonization events, such as the HGF/Met axis and the WW domaincontaining oxidoreductase (Wwox) gene, and therapies targeting bone metastases. Hashimoto and his colleagues suggested that miRNAs secreted by cancer cells in the bone microenvironment induced bone metastasis phenotypes (Hashimoto et al., 2018). Interestingly, the implantation of miR-940-overexpressing MDAMB-231 cells induced extensive osteoblastic lesions in the resultant tumors by facilitating osteogenic differentiation of host mesenchymal cells, even though MDA-MB-231 breast cancer cells have commonly been considered an osteolyticinducing cancer cell line. Tiedemann et al. (2019) identified that extracellular L-plastin and peroxiredoxin 4 (PRDX4) played a specific role in stimulating osteoclastogenesis, thus promoting osteolysis during tumor metastasis to bone, which suggested that information regarding the expression of these proteins might be especially useful in the treatment of cancers that frequently metastasize to bone. Another study demonstrated that miR-20a-5p, transferred from breast cancer cell-derived EVs, enhanced the proliferation and differentiation of osteoclasts by targeting SRCIN1, thereby laying scientific foundations for the development of EV- or miR-20a-5p-targeted therapeutic interventions in patients with breast cancer progression (Guo et al., 2019). Breast cancer cell-derived EVs, associated with the formation of a pre-metastatic niche via the transfer of miR-21 and the regulation of PDCD4 protein levels, play an important role in promoting breast cancer bone metastasis (Yuan et al., 2021). Moreover, breast cancer cell (MDA-MB-231) EVs inhibited osteoblast differentiation and reduced cell numbers and activities by increasing osteoclast formation in a RANKLindependent manner. In osteoblasts, breast cancer cell EVs were shown to enhance transcription and increase angiogenesis and osteoclastogenesis (Loftus et al., 2020).

\section{Extracellular Vesicles and Lung Cancer Metastasis to Bone}

Lung cancer has currently one of the highest incidences of malignancy worldwide. Bone is a distant metastatic site for lung cancer, and the most common sites for lung cancer bone metastases include the spine, chest, and pelvis (Tam et al., 2020). The main routes of bone metastases occur through blood and direct local infiltration with rich blood supplies in the marrow cavity and higher adhesion molecule expression in malignant tumor cells, and a large number of growth factors in bone (Xu S. et al., 2020). After metastatic bone disease, patients develop a series of bone-related events, including pain, hypercalcemia, dyskinesia, spinal cord compression, and pathologic fractures, all of which severely affect patient quality of life (Huang et al., 2020). Taverna et al. (2017) observed that non-small-cell lung cancer (NSCLC) EVs that activated the amphiregulin (AREG)-induced epidermal growth factor (EGFR) pathway in pre-osteoclasts, in turn, caused higher RANKL expression in osteocytes. RANKL could also induce the expression of proteolytic enzymes involved in osteoclastogenesis and thereby trigger a vicious cycle in the process of osteolytic bone metastasis (Taverna et al., 2017). Xu et al. (2018) showed that lung adenocarcinoma-derived exosomal miR-21 showed promise as a facilitator of osteoclastogenesis and thus as a potential therapeutic target of bone metastasis. Understanding new advances in the diagnosis and treatment of lung cancer metastasis to bone holds great significance for prolonging survival and improving therapeutic effects in patients with lung cancer with metastasis to bone.

\section{Extracellular Vesicles and Multiple Myeloma}

Multiple myeloma (MM) is characterized as a proliferation of malignant clonal plasma cells that can infiltrate bone marrow and replace marrow cells. This malignancy also causes the mass production of abnormal immunoglobulins and destruction of bone, producing a series of clinical symptoms and signs that seriously threaten the quality of life and lifespan of middleaged and elderly adults (Garces et al., 2020; Jeon et al., 2020). At present, the primary therapies include combined 
chemotherapies and stem cell transplants (Coffey et al., 2019). Since the proliferation ratio of tumor cells and formation of multiple resistant strains is low in MM, the therapeutic efficacy of clinical treatments remains less than ideal. Thus, finding a novel therapeutic target is urgently needed.

There are many factors that cause MM bone disease, high osteoclastic activity is the main reason, although many other factors are involved (Abdi et al., 2013; Rossi et al., 2013; Hameed et al., 2014). The proliferation of MM is markedly related to the increase in the number and activity of osteoclasts. This relationship maintains a balance between the abnormal cycle of bone destruction and tumor cell survival. A report by Raimondi et al. (2015) stated that EVs derived from MM were also able to regulate the migration and differentiation of osteoclasts. Additionally, MM-derived EVs have been shown to have two primary functions. One, it can promote the appearance of osteoclasts, and two, it can help improve bone resorption of mature osteoclast-like cells. Moreover, Garimella et al. (2014) reported that highly invasive and metastatic osteosarcoma 143B cells could produce EVs by using ionomycin and forskolin to actively mobilize intracellular calcium or increase cyclic adenosine monophosphate (cAMP) levels. Raimondo et al. (2019) reported that AREG was specifically enriched in EVs from MM cells and that EV-derived AREG participated in MMinduced osteoclastogenesis by activating EGFR ligands in preosteoclasts. The above studies have proven that EVs are the main factors of communication between MM cells and the bone marrow microenvironment. More importantly, the above conclusions support the role of tumor cell-derived microvesicles in disease aggressiveness and cancer progression.

\section{Extracellular Vesicles and Acute Myelocytic Leukemia}

Acute myelocytic leukemia (AML) is a heterogeneous clonal hematopoietic stem cell disease mainly characterized by the severe blockage of myeloid cell differentiation, rapid clonal cell proliferation, and the infiltration of other organs by immature myeloid bone marrow cells (Lu et al., 2017; Zhou et al., 2020). The incidence of AML increases with age. AML is considered the most common acute leukemia in adults, with a low incidence in children, only accounting for $15 \%$ 20\% of childhood leukemias (Zhou et al., 2020). Recently, Kumar et al. (2018) analyzed a new AML mouse model and demonstrated the niche transformation model. The study results indicated that the hematopoietic microenvironment could be altered with the help of EV transfer (through the Dickkopf WNT signaling pathway inhibitor 1 (DKK1) gene). It was also found that normal niches could be turned into malignant niches. In addition, mesenchymal progenitor cells increased, and osteogenesis and bone formation were blocked after injecting AML-derived EVs into mice. The proliferation rate of AML cells was also shown to be accelerated by the AML-derived EVs. However, AML-derived EVs could be destroyed by Rab27a targeting, which provided inhibitory effects that could significantly delay the appearance of leukemia (Kumar et al., 2018). In addition, DKK1 was found to belong to a normal hematopoietic and osteogenic inhibitory factor.
Therefore, related reports stated that bone cell loss was due to the stimulating effects of AML-derived EVs on DKK1 (Kumar et al., 2018). Thus, targeting EVs could represent a new strategy for cancer treatments. The effective suppression of the hematopoietic microenvironment might be a crucial new direction for the control of malignant blood cell proliferation.

\section{Extracellular Vesicles and Melanoma Metastasis to Bone}

Malignant melanoma $(\mathrm{Mm})$ is a highly malignant melanocyte tumor that accounts for $90 \%$ of skin malignancies causing death (Broggini et al., 2020; Mannavola et al., 2020). Mm is formed from the malignant transformation of melanocytes located at the epidermal basement membrane. This tumor is more common on the face and heels and primarily progresses from the malignant transformation of nevi or pigmented spots (Wilson et al., 2020). Mm is highly malignant and vulnerable to lymphatic and blood tract metastases in the early stages. Mm often metastasizes to the liver, lung, kidney, and brain, and a few reports have demonstrated metastasis to the gastrointestinal tract and ovaries. However, metastases to bone marrow have only rarely been reported (Wilson et al., 2020). Mannavola et al. (2019) demonstrated that tumor-derived EVs reprogrammed the innate osteotropism of melanoma cells in vitro by upregulating membrane CXCR7. These results provide the possible identification of targets for future drug development to skeletal metastases of malignant melanoma (Mannavola et al., 2019). Peinado et al. (2012) indicated that EVs from highly metastatic melanoma increased the metastatic behaviors of primary tumors by permanently "educating" bone marrow progenitors via the MET receptor. Melanomaderived EVs also induced vascular leakage in pre-metastatic lesions and reprogrammed bone marrow progenitors toward a c-Kit+Tie2+MET+ pro-vasculogenic phenotype (Peinado et al., 2012). Lower MET expression in EVs weakened the prometastatic behaviors of bone marrow cells (Peinado et al., 2012). All of these studies implied that melanoma-derived EVs could facilitate bone metastases using some factors, such as MET.

\section{CONCLUSION AND OUTLOOK}

Bone metastasis, as the major complication in patients with advanced tumors, characterized by osteolytic lesion, often occurring in chest bones. Since metastasized cancer cells can damage bone marrow hematopoiesis and bone structure, bone metastasis becomes the major symptom in advanced diseases, as well as the leading cause of death (Coleman et al., 2020). The destruction of the hemopoietic system by tumor cells mainly results in anemia and an increased infection tendency. Excessive bone growth causes local pain, fracture, and spinal cord compression; even paraplegia can be seen with severe bone damage and not only accelerates the death of patients but also seriously reduces quality of life (Mukaida et al., 2020). The discovery of novel biomarkers and targets to control metastatic bone disease is urgently needed. EVs have been reported to be biomarkers for cancer diagnoses and targets for novel therapies. 
EVs, as carriers of protein, RNAs, and other bioactive molecules, serve as a tool for cell-to-cell communications and could be effective in regulating the signaling pathways or biological behaviors of recipient cells. This review summarizes the roles of tumor-derived EVs in bone metastasis and concludes that proteins and RNAs in EVs derived from tumor cells could enhance tumor invasion and metastasis and might be useful as targets for cancer therapy and the inhibition of bone metastases.

Although research has proven a vital role for EVs in tumor metastasis to bones, many problems still need to be investigated in future studies. These include the roles of tumor-derived EV compositions (including RNA and DNA) in determining bone-specific metastases, whether tumor metastasis could be prevented by inhibiting the secretion of tumor-derived EVs, especially in bone metastases and other organs that damage bodily functions, and if clinical transformations could be carried out using targeted therapies for tumor metastasis to bone based on discovered molecular mechanisms. Solving these issues will help highlight the underlying mechanisms of bone metastases. Future therapeutic strategies could involve a combination of several drugs that might block multiple targets or pathways simultaneously to improve quality of life, prolong survival, and provide greater therapeutic benefits for patients with bone metastases.

\section{REFERENCES}

Abdi, J., Chen, G., and Chang, H. (2013). Drug resistance in multiple myeloma: latest findings and new concepts on molecular mechanisms. Oncotarget 4, 2186-2207. doi: 10.18632/oncotarget.1497

Aguirre Ghiso, J. A. (2002). Inhibition of FAK signaling activated by urokinase receptor induces dormancy in human carcinoma cells in vivo. Oncogene 21, 2513-2524. doi: 10.1038/sj.onc. 1205342

Aguirre Ghiso, J. A., Kovalski, K., and Ossowski, L. (1999). Tumor dormancy induced by downregulation of urokinase receptor in human carcinoma involves integrin and MAPK signaling. J. Cell Biol. 147, 89-104. doi: 10.1083/jcb.147. 1.89

Archer, M., Dogra, N., and Kyprianou, N. (2020). Inflammation as a driver of prostate cancer metastasis and therapeutic resistance. Cancers (Basel) 12:2984. doi: $10.3390 /$ cancers 12102984

Baroni, S., Romero-Cordoba, S., Plantamura, I., Dugo, M., D’Ippolito, E., Cataldo, A., et al. (2016). Exosome-mediated delivery of miR-9 induces cancer-associated fibroblast-like properties in human breast fibroblasts. Cell Death Dis. 7:e2312. doi: 10.1038/cddis.2016.224

Bendinelli, P., Maroni, P., Matteucci, E., and Desiderio, M. A. (2017). Epigenetic regulation of $\mathrm{HGF} / \mathrm{Met}$ receptor axis is critical for the outgrowth of bone metastasis from breast carcinoma. Cell Death Dis. 8:e2578. doi: 10.1038/cddis. 2016.403

Borel, M., Lollo, G., Magne, D., Buchet, R., Brizuela, L., and Mebarek, S. (2020). Prostate cancer-derived exosomes promote osteoblast differentiation and activity through phospholipase D2. Biochim. Biophys. Acta Mol. Basis Dis. 1866:165919. doi: 10.1016/j.bbadis.2020.165919

Boucher, J., Balandre, A. C., Debant, M., Vix, J., Harnois, T., Bourmeyster, N., et al. (2020). Cx43 present at the leading edge membrane governs promigratory effects of osteoblast-conditioned medium on human prostate cancer cells in the context of bone metastasis. Cancers (Basel) 12:3013. doi: 10.3390/ cancers12103013

Broggini, T., Piffko, A., Hoffmann, C. J., Ghori, A., Harms, C., Adams, R. H., et al. (2020). Ephrin-B2-EphB4 communication mediates tumor-endothelial cell interactions during hematogenous spread to spinal bone in a melanoma metastasis model. Oncogene 39, 7063-7075. doi: 10.1038/s41388-020-01473-y

\section{AUTHOR CONTRIBUTIONS}

SL and WW contributed to original draft preparation, allocation, revision, supplement, and edition. Both authors have read and agreed to the published version of the manuscript.

\section{FUNDING}

This work was supported by the Natural Science Foundation of Liaoning Province (2020-MS-058) and the Shenyang Young and Middle-Aged Scientific and Technological Innovation Talent Support Plan (RC190456).

\section{ACKNOWLEDGMENTS}

We thank the generous support of the Liaoning Cancer Hospital \& Institute (Shenyang) and China Medical University (Shenyang). We also thank Chaonan Sun for her numerous constructive comments in the process of writing this manuscript.

Browne, G., Taipaleenmaki, H., Stein, G. S., Stein, J. L., and Lian, J. B. (2014). MicroRNAs in the control of metastatic bone disease. Trends Endocrinol. Metab. 25, 320-327. doi: 10.1016/j.tem.2014.03.014

Cheng, J., Meng, J., Zhu, L., and Peng, Y. (2020). Exosomal noncoding RNAs in Glioma: biological functions and potential clinical applications. Mol. Cancer 19:66. doi: 10.1186/s12943-020-01189-3

Coffey, D. G., Wu, Q. V., Towlerton, A. M. H., Ornelas, S., Morales, A. J., Xu, Y., et al. (2019). Ultradeep, targeted sequencing reveals distinct mutations in blood compared to matched bone marrow among patients with multiple myeloma. Blood Cancer J. 9:77. doi: 10.1038/s41408-019-0238-0

Coleman, R. E., Croucher, P. I., Padhani, A. R., Clezardin, P., Chow, E., Fallon, M., et al. (2020). Bone metastases. Nat. Rev. Dis. Primers 6:83. doi: 10.1038/s41572020-00216-3

Colletti, M., Tomao, L., Galardi, A., Paolini, A., Di Paolo, V., De Stefanis, C., et al. (2020). Neuroblastoma-secreted exosomes carrying miR375 promote osteogenic differentiation of bone-marrow mesenchymal stromal cells. J. Extracell. Vesicles 9:1774144. doi: 10.1080/20013078.2020. 1774144

Cossetti, C., Lugini, L., Astrologo, L., Saggio, I., Fais, S., and Spadafora, C. (2014). Soma-to-germline transmission of RNA in mice xenografted with human tumour cells: possible transport by exosomes. PLoS One 9:e101629. doi: 10. 1371/journal.pone.0101629

Croucher, P. I., McDonald, M. M., and Martin, T. J. (2016). Bone metastasis: the importance of the neighbourhood. Nat. Rev. Cancer 16, 373-386. doi: 10.1038/ nrc. 2016.44

Dai, J., Escara-Wilke, J., Keller, J. M., Jung, Y., Taichman, R. S., Pienta, K. J., et al. (2019). Primary prostate cancer educates bone stroma through exosomal pyruvate kinase M2 to promote bone metastasis. J. Exp. Med. 216, 2883-2899. doi: 10.1084/jem.20190158

Dai, J., Su, Y., Zhong, S., Cong, L., Liu, B., Yang, J., et al. (2020). Exosomes: key players in cancer and potential therapeutic strategy. Signal. Transduct. Target Ther. 5:145. doi: 10.1038/s41392-020-00261-0

Dormady, S. P., Zhang, X. M., and Basch, R. S. (2000). Hematopoietic progenitor cells grow on 3T3 fibroblast monolayers that overexpress growth arrest-specific gene-6 (GAS6). Proc. Natl. Acad. Sci. U.S.A. 97, 12260-12265. doi: 10.1073/ pnas.97.22.12260 
Esposito, M., and Kang, Y. (2014). Targeting tumor-stromal interactions in bone metastasis. Pharmacol. Ther. 141, 222-233. doi: 10.1016/j.pharmthera.2013.10. 006

Feuerer, M., Rocha, M., Bai, L., Umansky, V., Solomayer, E. F., Bastert, G., et al. (2001). Enrichment of memory T cells and other profound immunological changes in the bone marrow from untreated breast cancer patients. Int. J. Cancer 92, 96-105.

Fico, F., and Santamaria-Martinez, A. (2020). TGFBI modulates tumour hypoxia and promotes breast cancer metastasis. Mol. Oncol. 14, 3198-3210. doi: 10 . 1002/1878-0261.12828

Fu, F., Jiang, W., Zhou, L., and Chen, Z. (2018). Circulating exosomal miR-17-5p and miR-92a-3p predict pathologic stage and grade of colorectal cancer. Transl Oncol 11, 221-232. doi: 10.1016/j.tranon.2017.12.012

Garces, J. J., Simicek, M., Vicari, M., Brozova, L., Burgos, L., Bezdekova, R., et al. (2020). Transcriptional profiling of circulating tumor cells in multiple myeloma: a new model to understand disease dissemination. Leukemia 34, 589-603. doi: 10.1038/s41375-019-0588-4

Garimella, R., Washington, L., Isaacson, J., Vallejo, J., Spence, M., Tawfik, O., et al. (2014). Extracellular membrane vesicles derived from 143B osteosarcoma cells contain pro-osteoclastogenic cargo: a novel communication mechanism in osteosarcoma bone microenvironment. Transl. Oncol. 7, 331-340. doi: 10.1016/ j.tranon.2014.04.011

Goto, T., Fujiya, M., Konishi, H., Sasajima, J., Fujibayashi, S., Hayashi, A., et al. (2018). An elevated expression of serum exosomal microRNA-191, - 21, -451a of pancreatic neoplasm is considered to be efficient diagnostic marker. BMC Cancer 18:116. doi: 10.1186/s12885-018-4006-5

Grudowska, A., Czaplinska, D., Polom, W., Matuszewski, M., Sadej, R., and Skladanowski, A. C. (2017). Tetraspanin CD151 mediates communication between PC3 prostate cancer cells and osteoblasts. Acta Biochim. Pol. 64, 135-141. doi: 10.18388/abp.2016_1356

Guise, T. A., Mohammad, K. S., Clines, G., Stebbins, E. G., Wong, D. H., Higgins, L. S., et al. (2006). Basic mechanisms responsible for osteolytic and osteoblastic bone metastases. Clin. Cancer Res. 12(Pt 2), 6213s-6216s. doi: 10.1158/10780432.CCR-06-1007

Guo, L., Zhu, Y., Li, L., Zhou, S., Yin, G., Yu, G., et al. (2019). Breast cancer cellderived exosomal miR-20a-5p promotes the proliferation and differentiation of osteoclasts by targeting SRCIN1. Cancer Med. 8, 5687-5701. doi: 10.1002/cam4. 2454

Hameed, A., Brady, J. J., Dowling, P., Clynes, M., and O'Gorman, P. (2014). Bone disease in multiple myeloma: pathophysiology and management. Cancer Growth Metastasis 7, 33-42. doi: 10.4137/CGM.S16817

Hashimoto, K., Ochi, H., Sunamura, S., Kosaka, N., Mabuchi, Y., Fukuda, T., et al. (2018). Cancer-secreted hsa-miR-940 induces an osteoblastic phenotype in the bone metastatic microenvironment via targeting ARHGAP1 and FAM134A. Proc. Natl. Acad. Sci. U.S.A. 115, 2204-2209. doi: 10.1073/pnas.171736 3115

Hiraga, T. (2019). Bone metastasis: Interaction between cancer cells and bone microenvironment. J. Oral Biosci. 61, 95-98. doi: 10.1016/j.job.2019.02.002

Hirshberg, A., Berger, R., Allon, I., and Kaplan, I. (2014). Metastatic tumors to the jaws and mouth. Head Neck Pathol. 8, 463-474. doi: 10.1007/s12105-0140591-Z

Hsu, Y. L., Hung, J. Y., Chang, W. A., Lin, Y. S., Pan, Y. C., Tsai, P. H., et al. (2017). Hypoxic lung cancer-secreted exosomal miR-23a increased angiogenesis and vascular permeability by targeting prolyl hydroxylase and tight junction protein ZO-1. Oncogene 36, 4929-4942. doi: 10.1038/onc.2017.105

Huang, L., Jiang, X. L., Liang, H. B., Li, J. C., Chin, L. H., Wei, J. P., et al. (2020). Genetic profiling of primary and secondary tumors from patients with lung adenocarcinoma and bone metastases reveals targeted therapy options. Mol. Med. 26:88. doi: 10.1186/s10020-020-00197-9

Huyan, T., Li, H., Peng, H., Chen, J., Yang, R., Zhang, W., et al. (2020). Extracellular vesicles - advanced nanocarriers in cancer therapy: progress and achievements. Int. J. Nanomedicine 15, 6485-6502. doi: 10.2147/IJN.S238099

Inder, K. L., Ruelcke, J. E., Petelin, L., Moon, H., Choi, E., Rae, J., et al. (2014). Cavin-1/PTRF alters prostate cancer cell-derived extracellular vesicle content and internalization to attenuate extracellular vesicle-mediated osteoclastogenesis and osteoblast proliferation. J Extracell Vesicles 3:23784. doi: 10.3402/jev.v3.23784
Jeon, H. L., Oh, I. S., Baek, Y. H., Yang, H., Park, J., Hong, S., et al. (2020). Zoledronic acid and skeletal-related events in patients with bone metastatic cancer or multiple myeloma. J. Bone Miner. Metab. 38, 254-263. doi: 10.1007/ s00774-019-01052-6

Kalluri, R. (2016). The biology and function of exosomes in cancer. J. Clin. Invest. 126, 1208-1215. doi: 10.1172/JCI81135

Kalluri, R., and LeBleu, V. S. (2020). The biology, function, and biomedical applications of exosomes. Science 367:eaau6977. doi: 10.1126/science.aau6 977

Kamalakar, A., Washam, C. L., Akel, N. S., Allen, B. J., Williams, D. K., Swain, F. L., et al. (2017). PTHrP(12-48) modulates the bone marrow microenvironment and suppresses human osteoclast differentiation and lifespan. J. Bone Miner. Res. 32, 1421-1431. doi: 10.1002/jbmr.3142

Kang, Y. (2016). Dissecting tumor-stromal interactions in breast cancer bone metastasis. Endocrinol. Metab. (Seoul) 31, 206-212. doi: 10.3803/EnM.2016.31. 2.206

Karayazi Atici, O., Govindrajan, N., Lopetegui-Gonzalez, I., and Shemanko, C. S. (2020). Prolactin: a hormone with diverse functions from mammary gland development to cancer metastasis. Semin. Cell Dev. Biol. doi: 10.1016/j.semcdb. 2020.10.005 [Epub ahead of print].

Kelly, T., Suva, L. J., Huang, Y., Macleod, V., Miao, H. Q., Walker, R. C., et al. (2005). Expression of heparanase by primary breast tumors promotes bone resorption in the absence of detectable bone metastases. Cancer Res. 65, 57785784. doi: 10.1158/0008-5472.CAN-05-0749

Kianercy, A., and Pienta, K. J. (2016). Positive feedback loops between inflammatory, bone and cancer cells during metastatic niche construction. $A d v$. Exp. Med. Biol. 936, 137-148. doi: 10.1007/978-3-319-42023-3_7

Kim, H. J., Kim, H. J., Choi, Y., Bae, M. K., Hwang, D. S., Shin, S. H., et al. (2019). Zoledronate enhances osteocyte-mediated osteoclast differentiation by IL-6/RANKL Axis. Int. J. Mol. Sci. 20:1467. doi: 10.3390/ijms20061467

Kobayashi, A., Okuda, H., Xing, F., Pandey, P. R., Watabe, M., Hirota, S., et al. (2011). Bone morphogenetic protein 7 in dormancy and metastasis of prostate cancer stem-like cells in bone. J. Exp. Med. 208, 2641-2655. doi: 10.1084/jem. 20110840

Krzeszinski, J. Y., and Wan, Y. (2015). New therapeutic targets for cancer bone metastasis. Trends Pharmacol. Sci. 36, 360-373. doi: 10.1016/j.tips.2015.04.006

Kumar, B., Garcia, M., Weng, L., Jung, X., Murakami, J. L., Hu, X., et al. (2018). Acute myeloid leukemia transforms the bone marrow niche into a leukemia-permissive microenvironment through exosome secretion. Leukemia 32, 575-587. doi: 10.1038/leu.2017.259

Lang, C., Dai, Y., Wu, Z., Yang, Q., He, S., Zhang, X., et al. (2020). SMAD3/SP1 complex-mediated constitutive active loop between lncRNA PCAT7 and TGF$\beta$ signaling promotes prostate cancer bone metastasis. Mol. Oncol. 14, 808-828. doi: 10.1002/1878-0261.12634

Laranga, R., Duchi, S., Ibrahim, T., Guerrieri, A. N., Donati, D. M., and Lucarelli, E. (2020). Trends in bone metastasis modeling. Cancers (Basel) 12:2315. doi: $10.3390 /$ cancers 12082315

Le, M. T., Hamar, P., Guo, C., Basar, E., Perdigao-Henriques, R., Balaj, L., et al. (2014). miR-200-containing extracellular vesicles promote breast cancer cell metastasis. J. Clin. Invest. 124, 5109-5128. doi: 10.1172/JCI75695

LeBleu, V. S., and Kalluri, R. (2020). Exosomes as a multicomponent biomarker platform in cancer. Trends Cancer 6, 767-774. doi: 10.1016/j.trecan.2020.03. 007

Li, M., Li, S., Du, C., Zhang, Y., Li, Y., Chu, L., et al. (2020). Exosomes from different cells: Characteristics, modifications, and therapeutic applications. Eur. J. Med. Chem. 207:112784. doi: 10.1016/j.ejmech.2020.112784

Li, S. L., An, N., Liu, B., Wang, S. Y., Wang, J. J., and Ye, Y. (2019). Exosomes from LNCaP cells promote osteoblast activity through miR-375 transfer. Oncol. Lett. 17, 4463-4473. doi: 10.3892/ol.2019.10110

Lim, P. K., Bliss, S. A., Patel, S. A., Taborga, M., Dave, M. A., Gregory, L. A., et al. (2011). Gap junction-mediated import of microRNA from bone marrow stromal cells can elicit cell cycle quiescence in breast cancer cells. Cancer Res. 71, 1550-1560. doi: 10.1158/0008-5472.CAN-10-2372

Lipton, A. (2006). Future treatment of bone metastases. Clin. Cancer Res. 12(Pt 2), 6305s-6308s. doi: 10.1158/1078-0432.CCR-06-1157

Liu, D., Aguirre Ghiso, J., Estrada, Y., and Ossowski, L. (2002). EGFR is a transducer of the urokinase receptor initiated signal that is required for in vivo 
growth of a human carcinoma. Cancer Cell 1, 445-457. doi: 10.1016/s15356108(02)00072-7

Liu, Z., Wang, L., Xu, H., Du, Q., Li, L., Wang, L., et al. (2020). Heterogeneous responses to mechanical force of prostate cancer cells inducing different metastasis patterns. Adv. Sci. (Weinh) 7:1903583. doi: 10.1002/advs. 201903583

Loftus, A., Cappariello, A., George, C., Ucci, A., Shefferd, K., Green, A., et al. (2020). Extracellular vesicles from osteotropic breast cancer cells affect bone resident cells. J. Bone Miner. Res. 35, 396-412. doi: 10.1002/jbmr.3891

Logozzi, M., Angelini, D. F., Giuliani, A., Mizzoni, D., Di Raimo, R., Maggi, M., et al. (2019a). Increased plasmatic levels of PSA-expressing exosomes distinguish prostate cancer patients from benign prostatic hyperplasia: a prospective study. Cancers 11:1449. doi: 10.3390/cancers11101449

Logozzi, M., Angelini, D. F., Iessi, E., Mizzoni, D., and Fais, S. (2017). Increased psa expression on prostate cancer exosomes in in vitro condition and in cancer patients. Cancer Lett. 403, 318-329. doi: 10.1016/j.canlet.2017.06.036

Logozzi, M., Capasso, C., Di Raimo, R., Del Prete, S., Mizzoni, D., Falchi, M., et al. (2019b). Prostate cancer cells and exosomes in acidic condition show increased carbonic anhydrase IX expression and activity. J. Enzyme Inhibit. Med. Chem. 34, 272-278. doi: 10.1080/14756366.2018.1538980

Logozzi, M., Milito, A. D., Lugini, L., Borghi, M., Calabrò, L., Spada, M., et al. (2009). High levels of exosomes expressing cd63 and caveolin-1 in plasma of melanoma patients. PLoS One 4:e5219. doi: 10.1371/journal.pone.0005219

Logozzi, M., Mizzoni, D., Angelini, D. F., Di Raimo, R., Falchi, M., Battistini, L., et al. (2018). Microenvironmental $\mathrm{pH}$ and exosome levels interplay in human cancer cell lines of different histotypes. Cancers(Basel) 10:370. doi: 10.3390/ cancers 10100370

Logozzi, M., Spugnini, E., Mizzoni, D., Di Raimo, R., and Fais, S. (2019c). Extracellular acidity and increased exosome release as key phenotypes of malignant tumors. Cancer Metastasis Rev. 38, 93-101. doi: 10.1007/s10555-01909783-8

Lu, J. W., Hsieh, M. S., Hou, H. A., Chen, C. Y., Tien, H. F., and Lin, L. I. (2017). Overexpression of SOX 4 correlates with poor prognosis of acute myeloid leukemia and is leukemogenic in zebrafish. Blood Cancer J. 7:e593. doi: 10.1038/ bcj. 2017.74

Lu, X., Mu, E., Wei, Y., Riethdorf, S., Yang, Q., Yuan, M., et al. (2011). VCAM1 promotes osteolytic expansion of indolent bone micrometastasis of breast cancer by engaging alpha4beta1-positive osteoclast progenitors. Cancer Cell 20, 701-714. doi: 10.1016/j.ccr.2011.11.002

Lugini, L., Valtieri, M., Federici, C., Cecchetti, S., Meschini, S., Condello, M., et al. (2016). Exosomes from human colorectal cancer induce a tumor-like behavior in colonic mesenchymal stromal cells. Oncotarget 7, 50086-50098. doi: 10.18632/oncotarget.10574

Ma, R. Y., Zhang, H., Li, X. F., Zhang, C. B., Selli, C., Tagliavini, G., et al. (2020). Monocyte-derived macrophages promote breast cancer bone metastasis outgrowth. J. Exp. Med. 217:e20191820. doi: 10.1084/jem.20191820

Malladi, S., Macalinao, D. G., Jin, X., He, L., Basnet, H., Zou, Y., et al. (2016). Metastatic latency and immune evasion through autocrine inhibition of WNT. Cell 165, 45-60. doi: 10.1016/j.cell.2016.02.025

Mannavola, F., Mandala, M., Todisco, A., Sileni, V. C., Palla, M., Minisini, A. M., et al. (2020). An italian retrospective survey on bone metastasis in melanoma: impact of immunotherapy and radiotherapy on survival. Front. Oncol. 10:1652. doi: $10.3389 /$ fonc. 2020.01652

Mannavola, F., Tucci, M., Felici, C., Passarelli, A., D’Oronzo, S., and Silvestris, F. (2019). Tumor-derived exosomes promote the in vitro osteotropism of melanoma cells by activating the SDF-1/CXCR4/CXCR7 axis. J. Transl. Med. 17:230. doi: 10.1186/s12967-019-1982-4

Marazzi, F., Orlandi, A., Manfrida, S., Masiello, V., Di Leone, A., Massaccesi, M., et al. (2020). Diagnosis and treatment of bone metastases in breast cancer: radiotherapy, local approach and systemic therapy in a guide for clinicians. Cancers (Basel) 12:2390. doi: 10.3390/cancers 12092390

Mashouri, L., Yousefi, H., Aref, A. R., Ahadi, A. M., Molaei, F., and Alahari, S. K. (2019). Exosomes: composition, biogenesis, and mechanisms in cancer metastasis and drug resistance. Mol. Cancer 18:75. doi: 10.1186/s12943-0190991-5

Mathew, M., Zade, M., Mezghani, N., Patel, R., Wang, Y., and Momen-Heravi, F. (2020). Extracellular vesicles as biomarkers in cancer immunotherapy. Cancers (Basel) 12:2825. doi: 10.3390/cancers12102825
Mathieu, M., Martin-Jaular, L., Lavieu, G., and Thery, C. (2019). Specificities of secretion and uptake of exosomes and other extracellular vesicles for cell-to-cell communication. Nat. Cell Biol. 21, 9-17. doi: 10.1038/s41556-018-0250-9

Melo, S. A., Luecke, L. B., Kahlert, C., Fernandez, A. F., Gammon, S. T., Kaye, J., et al. (2015). Glypican-1 identifies cancer exosomes and detects early pancreatic cancer. Nature 523, 177-182. doi: 10.1038/nature14581

Mukaida, N., Zhang, D., and Sasaki, S. I. (2020). Emergence of cancer-associated fibroblasts as an indispensable cellular player in bone metastasis process. Cancers (Basel) 12:2896. doi: 10.3390/cancers 12102896

Mulcrone, P. L., Campbell, J. P., Clement-Demange, L., Anbinder, A. L., Merkel, A. R., Brekken, R. A., et al. (2017). Skeletal colonization by breast cancer cells is stimulated by an osteoblast and beta2AR-dependent neo-angiogenic switch. J. Bone Miner. Res. 32, 1442-1454. doi: 10.1002/jbmr.3133

Naseri, M., Bozorgmehr, M., Zoller, M., Ranaei Pirmardan, E., and Madjd, Z. (2020). Tumor-derived exosomes: the next generation of promising cell-free vaccines in cancer immunotherapy. Oncoimmunology 9:1779991. doi: 10.1080/ 2162402X.2020.1779991

Osti, D., Del Bene, M., Rappa, G., Santos, M., Matafora, V., Richichi, C., et al. (2018). Clinical significance of extracellular vesicles in plasma from glioblastoma patients. Clin. Cancer Res. 25, 266-276. doi: 10.1158/1078-0432. CCR-18-1941

Pan, L., Liang, W., Fu, M., Huang, Z. H., Li, X., Zhang, W., et al. (2017). Exosomesmediated transfer of long noncoding RNA ZFAS1 promotes gastric cancer progression. J. Cancer Res. Clin. Oncol. 143, 991-1004. doi: 10.1007/s00432017-2361-2

Pang, Y., Su, L., Fu, Y., Jia, F., Zhang, C., Cao, X., et al. (2021). Inhibition of furin by bone targeting superparamagnetic iron oxide nanoparticles alleviated breast cancer bone metastasis. Bioact. Mater. 6, 712-720. doi: 10.1016/j.bioactmat. 2020.09.006

Park, S. B., Hwang, K. T., Chung, C. K., Roy, D., and Yoo, C. (2020). Causal Bayesian gene networks associated with bone, brain and lung metastasis of breast cancer. Clin. Exp. Metastasis 37, 657-674. doi: 10.1007/s10585-02010060-0

Parolini, I., Federici, C., Raggi, C., Lugini, L., Palleschi, S., De Milito, A., et al. (2009). Microenvironmental $\mathrm{pH}$ is a key factor for exosome traffic in tumor cells. J. Biol. Chem. 284, 34211-34222. doi: 10.1074/jbc.M109.041152

Pegtel, D. M., and Gould, S. J. (2019). Exosomes. Annu. Rev. Biochem. 88, 487-514. doi: 10.1146/annurev-biochem-013118-111902

Peinado, H., Aleckovic, M., Lavotshkin, S., Matei, I., Costa-Silva, B., MorenoBueno, G., et al. (2012). Melanoma exosomes educate bone marrow progenitor cells toward a pro-metastatic phenotype through MET. Nat. Med. 18, 883-891. doi: $10.1038 / \mathrm{nm} .2753$

Quayle, L., Ottewell, P. D., and Holen, I. (2015). Bone metastasis: molecular mechanisms implicated in tumour cell dormancy in breast and prostate cancer. Curr. Cancer Drug Targets 15, 469-480. doi: 10.2174/1568009615666150506092443

Raimondi, L., De Luca, A., Amodio, N., Manno, M., Raccosta, S., Taverna, S., et al. (2015). Involvement of multiple myeloma cell-derived exosomes in osteoclast differentiation. Oncotarget 6, 13772-13789. doi: 10.18632/oncotarget.3830

Raimondo, S., Saieva, L., Corrado, C., Fontana, S., Flugy, A., Rizzo, A., et al. (2015). Chronic myeloid leukemia-derived exosomes promote tumor growth through an autocrine mechanism. Cell Commun. Signal. 13:8. doi: 10.1186/s12964-0150086-x

Raimondo, S., Saieva, L., Vicario, E., Pucci, M., Toscani, D., Manno, M., et al. (2019). Multiple myeloma-derived exosomes are enriched of amphiregulin (AREG) and activate the epidermal growth factor pathway in the bone microenvironment leading to osteoclastogenesis. J. Hematol. Oncol 12:2. doi: 10.1186/s13045-018-0689-y

Ren, G., Esposito, M., and Kang, Y. (2015). Bone metastasis and the metastatic niche. J. Mol. Med. (Berl.) 93, 1203-1212. doi: 10.1007/s00109-015-1329-4

Rodríguez Zorrilla, S., Pérez-Sayans, M., Fais, S., Logozzi, M., Gallas Torreira, M., and García García, A. (2019). A pilot clinical study on the prognostic relevance of plasmatic exosomes levels in oral squamous cell carcinoma patients. Cancers 11:429. doi: 10.3390/cancers11030429

Rossi, M., Pitari, M. R., Amodio, N., Di Martino, M. T., Conforti, F., Leone, E., et al. (2013). miR-29b negatively regulates human osteoclastic cell differentiation and function: implications for the treatment of multiple myeloma-related bone disease. J. Cell Physiol. 228, 1506-1515. doi: 10.1002/jcp.24306 
Sawant, A., Hensel, J. A., Chanda, D., Harris, B. A., Siegal, G. P., Maheshwari, A., et al. (2012). Depletion of plasmacytoid dendritic cells inhibits tumor growth and prevents bone metastasis of breast cancer cells. J. Immunol. 189, 4258-4265. doi: 10.4049/jimmunol.1101855

Scimeca, M., Trivigno, D., Bonfiglio, R., Ciuffa, S., Urbano, N., Schillaci, O., et al. (2020). Breast cancer metastasis to bone: from epithelial to mesenchymal transition to breast osteoblast-like cells. Semin. Cancer Biol. doi: 10.1016/j. semcancer.2020.01.004 [Epub ahead of print].

Slomka, A., Mocan, T., Wang, B., Nenu, I., Urban, S. K., Gonzales-Carmona, M., et al. (2020). EVs as potential new therapeutic Tool/target in gastrointestinal cancer and HCC. Cancers (Basel) 12:3019. doi: 10.3390/cancers12103019

Sosa, M. S., Bragado, P., and Aguirre-Ghiso, J. A. (2014). Mechanisms of disseminated cancer cell dormancy: an awakening field. Nat. Rev. Cancer 14, 611-622. doi: 10.1038/nrc3793

Su, Z., Yang, Z., Xu, Y., Chen, Y., and Yu, Q. (2015). Apoptosis, autophagy, necroptosis, and cancer metastasis. Mol. Cancer 14:48. doi: 10.1186/s12943015-0321-5

Tam, A. H., Schepers, A. J., Qin, A., and Nachar, V. R. (2020). Impact of extendedinterval versus standard dosing of zoledronic acid on skeletal events in nonsmall-cell lung cancer and small-cell lung cancer patients with bone metastases. Ann. Pharmacother. doi: 10.1177/1060028020967629 [Epub ahead of print].

Tamura, T., Yoshioka, Y., Sakamoto, S., Ichikawa, T., and Ochiya, T. (2020). Extracellular vesicles in bone metastasis: key players in the tumor microenvironment and promising therapeutic targets. Int. J. Mol. Sci. 21:6680. doi: $10.3390 /$ ijms 21186680

Tang, M. K. S., Yue, P. Y. K., Ip, P. P., Huang, R. L., Lai, H. C., Cheung, A. N. Y., et al. (2018). Soluble E-cadherin promotes tumor angiogenesis and localizes to exosome surface. Nat. Commun. 9:2270. doi: 10.1038/s41467-018-04695-7

Taverna, S., Pucci, M., Giallombardo, M., Di Bella, M. A., Santarpia, M., Reclusa, P., et al. (2017). Amphiregulin contained in NSCLC-exosomes induces osteoclast differentiation through the activation of EGFR pathway. Sci. Rep. 7:3170. doi: 10.1038/s41598-017-03460-y

Terese, K., Marie, L., Anders, W., Emma, P., and Benedetta, B. (2016). Tumor cellderived exosomes from the prostate cancer cell line tramp-c1 impair osteoclast formation and differentiation. PLoS One 11:e0166284. doi: 10.1371/journal. pone. 0166284

Tiedemann, K., Sadvakassova, G., Mikolajewicz, N., Juhas, M., Sabirova, Z., Tabaries, S., et al. (2019). Exosomal release of L-plastin by breast cancer cells facilitates metastatic bone osteolysis. Transl. Oncol. 12, 462-474. doi: 10.1016/j. tranon.2018.11.014

Tomasetti, M., Lee, W., Santarelli, L., and Neuzil, J. (2017). Exosome-derived microRNAs in cancer metabolism: possible implications in cancer diagnostics and therapy. Exp. Mol. Med. 49:e285. doi: 10.1038/emm.2016.153

Tominaga, N., Kosaka, N., Ono, M., Katsuda, T., Yoshioka, Y., Tamura, K., et al. (2015). Brain metastatic cancer cells release microRNA-181c-containing extracellular vesicles capable of destructing blood-brain barrier. Nat. Commun. 6:6716. doi: 10.1038/ncomms7716

Vasconcelos, M. H., Caires, H. R., Abols, A., Xavier, C. P. R., and Line, A. (2019). Extracellular vesicles as a novel source of biomarkers in liquid biopsies for monitoring cancer progression and drug resistance. Drug Resist. Updat. 47:100647. doi: 10.1016/j.drup.2019.100647

Vicent, S., Perurena, N., Govindan, R., and Lecanda, F. (2015). Bone metastases in lung cancer. Potential novel approaches to therapy. Am. J. Respir. Crit. Care Med. 192, 799-809. doi: 10.1164/rccm.201503-0440SO

Wang, H., Tian, L., Liu, J., Goldstein, A., Bado, I., Zhang, W., et al. (2018). The osteogenic niche is a calcium reservoir of bone micrometastases and confers unexpected therapeutic vulnerability. Cancer Cell 34, 823-839.e7. doi: 10.1016/ j.ccell.2018.10.002

Wang, H., Yu, C., Gao, X., Welte, T., Muscarella, A. M., Tian, L., et al. (2015). The osteogenic niche promotes early-stage bone colonization of disseminated breast cancer cells. Cancer Cell 27, 193-210. doi: 10.1016/j.ccell.2014.1 1.017

Wang, M., Xia, F., Wei, Y., and Wei, X. (2020). Molecular mechanisms and clinical management of cancer bone metastasis. Bone Res. 8:30. doi: 10.1038/s41413020-00105-1

Waning, D. L., and Guise, T. A. (2014). Molecular mechanisms of bone metastasis and associated muscle weakness. Clin. Cancer Res. 20, 3071-3077. doi: 10.1158/ 1078-0432.CCR-13-1590
Weilbaecher, K. N., Guise, T. A., and McCauley, L. K. (2011). Cancer to bone: a fatal attraction. Nat Rev Cancer 11, 411-425. doi: 10.1038/nrc3055

Wilson, M. A., Zhong, J., Johannet, P., Lee, Y., Masub, N., Wechter, T., et al. (2020). Preliminary analysis of distinct clinical and biologic features of bone metastases in melanoma. Melanoma Res. 30, 492-499. doi: 10.1097/CMR. 0000000000000691

Wood, S. L., and Brown, J. E. (2020). Personal medicine and bone metastases: biomarkers, micro-RNAs and bone metastases. Cancers (Basel) 12:2109. doi: $10.3390 /$ cancers 12082109

Wortzel, I., Dror, S., Kenific, C. M., and Lyden, D. (2019). Exosome-mediated metastasis: communication from a distance. Dev. Cell 49, 347-360. doi: 10.1016/ j.devcel.2019.04.011

Wu, A. C., He, Y., Broomfield, A., Paatan, N. J., Harrington, B. S., Tseng, H. W., et al. (2016). CD169(+) macrophages mediate pathological formation of woven bone in skeletal lesions of prostate cancer. J. Pathol. 239, 218-230. doi: 10.1002/ path. 4718

Xiao, L., He, Y., Peng, F., Yang, J., and Yuan, C. (2020). Endometrial cancer cells promote M2-like macrophage polarization by delivering exosomal miRNA-21 under hypoxia condition. J. Immunol. Res. 2020:9731049. doi: 10.1155/2020/ 9731049

Xu, S., Cao, S., Geng, J., Wang, C., Meng, Q., and Yu, Y. (2020). High prognostic nutritional index (PNI) as a positive prognostic indicator for non-small cell lung cancer patients with bone metastasis. Clin. Respir. J. 15, 225-231. doi: $10.1111 /$ crj. 13288

Xu, Y., Liu, N., Wei, Y., Zhou, D., Lin, R., Wang, X., et al. (2020). Anticancer effects of miR-124 delivered by BM-MSC derived exosomes on cell proliferation, epithelial mesenchymal transition, and chemotherapy sensitivity of pancreatic cancer cells. Aging (Albany NY) 12, 19660-19676. doi: 10.18632/aging.103997

Xu, Z., Liu, X., Wang, H., Li, J., Dai, L., Li, J., et al. (2018). Lung adenocarcinoma cell-derived exosomal miR-21 facilitates osteoclastogenesis. Gene 666, 116-122. doi: 10.1016/j.gene.2018.05.008

Xue, P., Wu, Z., Wang, K., Gao, G., Zhuang, M., and Yan, M. (2020). Oncological outcome of combining cytoreductive prostatectomy and metastasis-directed radiotherapy in patients with prostate cancer and bone oligometastases: a retrospective cohort study. Cancer Manag. Res. 12, 8867-8873. doi: 10.2147/ CMAR.S270882

Yang, B., Feng, X., Liu, H., Tong, R., Wu, J., Li, C., et al. (2020). High-metastatic cancer cells derived exosomal miR92a-3p promotes epithelial-mesenchymal transition and metastasis of low-metastatic cancer cells by regulating PTEN/Akt pathway in hepatocellular carcinoma. Oncogene 39, 6529-6543. doi: 10.1038/ s41388-020-01450-5

Yang, E., Wang, X., Gong, Z., Yu, M., Wu, H., and Zhang, D. (2020). Exosome-mediated metabolic reprogramming: the emerging role in tumor microenvironment remodeling and its influence on cancer progression. Signal. Transduct. Target Ther. 5:242. doi: 10.1038/s41392-020-00359-5

Yao, D., Huang, L., Ke, J., Zhang, M., Xiao, Q., and Zhu, X. (2020). Bone metabolism regulation: Implications for the treatment of bone diseases. Biomed. Pharmacother. 129:110494. doi: 10.1016/j.biopha.2020.110494

Ye, Y., Li, S. L., Ma, Y. Y., Diao, Y. J., Yang, L., Su, M. Q., et al. (2017). Exosomal miR-141-3p regulates osteoblast activity to promote the osteoblastic metastasis of prostate cancer. Oncotarget 8, 94834-94849. doi: 10.18632/oncotarget.22014

Yi, M., Xu, L., Jiao, Y., Luo, S., Li, A., and Wu, K. (2020). The role of cancerderived microRNAs in cancer immune escape. J. Hematol. Oncol. 13:25. doi: 10.1186/s13045-020-00848-8

Yin, J. J., Pollock, C. B., and Kelly, K. (2005). Mechanisms of cancer metastasis to the bone. Cell Res. 15, 57-62. doi: 10.1038/sj.cr.7290266

Yuan, X., Qian, N., Ling, S., Li, Y., and Li, Y. (2021). Breast cancer exosomes contribute to pre-metastatic niche formation and promote bone metastasis of tumor cells. Theranostics 11, 1429-1445. doi: 10.7150/thno.45351

Zhang, D., Iwabuchi, S., Baba, T., Hashimoto, S. I., Mukaida, N., and Sasaki, S. I. (2020). Involvement of a transcription factor, Nfe2, in breast cancer metastasis to bone. Cancers (Basel) 12:3003. doi: 10.3390/cancers12103003

Zhang, W., Bado, I., Wang, H., Lo, H. C., and Zhang, X. H. (2019). Bone metastasis: find your niche and fit in. Trends Cancer 5, 95-110. doi: 10.1016/j.trecan.2018. 12.004

Zhang, Y., Bi, J., Huang, J., Tang, Y., Du, S., and Li, P. (2020). Exosome: a review of its classification, isolation techniques, storage, diagnostic and targeted therapy applications. Int. J. Nanomed. 15, 6917-6934. doi: 10.2147/IJN.S264498 
Zhao, X., Ren, Y., and Lu, Z. (2020). Potential diagnostic and therapeutic roles of exosomes in pancreatic cancer. Biochim. Biophys. Acta Rev. Cancer 1874:188414. doi: 10.1016/j.bbcan.2020.188414

Zhao, Z., Pi, Y., Jiang, L., Xiang, Y., Wei, J., Yang, P., et al. (2020). Deep neural network based artificial intelligence assisted diagnosis of bone scintigraphy for cancer bone metastasis. Sci. Rep. 10:17046. doi: 10.1038/ s41598-020-74135-4

Zheng, P., Chen, L., Yuan, X., Luo, Q., Liu, Y., Xie, G., et al. (2017). Exosomal transfer of tumor-associated macrophage-derived miR-21 confers cisplatin resistance in gastric cancer cells. J. Exp. Clin. Cancer Res. 36:53. doi: 10.1186/ s13046-017-0528-y

Zhou, W., Fong, M. Y., Min, Y., Somlo, G., Liu, L., Palomares, M. R., et al. (2014). Cancer-secreted miR-105 destroys vascular endothelial barriers to promote metastasis. Cancer Cell 25, 501-515. doi: 10.1016/j.ccr.2014.03.007
Zhou, X., Liang, S., Zhan, Q., Yang, L., Chi, J., and Wang, L. (2020). HSPG2 overexpression independently predicts poor survival in patients with acute myeloid leukemia. Cell Death Dis. 11:492. doi: 10.1038/s41419-020-2694-7

Conflict of Interest: The authors declare that the research was conducted in the absence of any commercial or financial relationships that could be construed as a potential conflict of interest.

Copyright (c) 2021 Li and Wang. This is an open-access article distributed under the terms of the Creative Commons Attribution License (CC BY). The use, distribution or reproduction in other forums is permitted, provided the original author(s) and the copyright owner(s) are credited and that the original publication in this journal is cited, in accordance with accepted academic practice. No use, distribution or reproduction is permitted which does not comply with these terms. 